\title{
Emergency surgery due to diaphragmatic hernia: case series and review
}

\author{
Mario Testini ${ }^{1 *} \mathbb{D}$, Antonia Girardi ${ }^{1}$, Roberta Maria Isernia', Angela De Palma², Giovanni Catalano', \\ Angela Pezzolla ${ }^{3}$ and Angela Gurrado ${ }^{1}$
}

\begin{abstract}
Background: Congenital diaphragmatic hernia $(\mathrm{CDH})$ is a congenital abnormality, rare in adults with a frequency of $0.17-6 \%$. Diaphragmatic rupture is an infrequent consequence of trauma, occurring in about $5 \%$ of severe closed thoraco-abdominal injuries. Clinical presentation ranges from asymptomatic cases to serious respiratory or gastrointestinal symptoms. Diagnosis depends on anamnesis, clinical signs and radiological investigations.

Methods: From May 2013 to June 2016, six cases (four females, two males; mean age 58 years) of diaphragmatic hernia were admitted to our Academic Department of General Surgery with respiratory and abdominal symptoms. Chest X-ray, barium studies and $C T$ scan were performed.

Results: Case 1 presented left diaphragmatic hernia containing transverse and descending colon. Case 2 showed left CDH which allowed passage of stomach, spleen and colon. Case 3 and 6 showed stomach in left hemithorax. Case 4 presented left diaphragmatic hernia which allowed passage of the spleen, left lobe of liver and transverse colon. Case 5 had stomach and spleen herniated into the chest. Emergency surgery was always performed. The hernia contents were reduced and defect was closed with primary repair or mesh. In all cases, post-operative courses were uneventful.

Conclusion: Overlapping abdominal and respiratory symptoms lead to diagnosis of diaphragmatic hernia, in patients with or without an history of trauma. Chest X-ray, CT scan and barium studies should be done to evaluate diaphragmatic defect, size, location and contents. Emergency surgical approach is mandatory reducing morbidity and mortality.
\end{abstract}

Keyword: Congenital diaphragmatic hernia, Diaphragmatic rupture, Mesh, Emergency surgery, Laparotomy, Thoracotomy

\section{Background}

Congenital diaphragmatic hernia $(\mathrm{CDH})$ is an abnormality found in $1 / 2500$ newborns, with a survival rate of $67 \%$ [1]. A primary characterization of $\mathrm{CDH}$ is that the diaphragm fails to form properly during embryogenesis. This incomplete formation of the diaphragm allows abdominal contents to herniate into the chest creating a mass-like effect that impedes lung development. Clinical presentation ranges from asymptomatic cases to serious respiratory or gastrointestinal symptoms, and sometimes haemodynamic instability. The broad spectrum of severity in patients with $\mathrm{CDH}$ is dependent on the degree of pulmonary hypoplasia and pulmonary

\footnotetext{
* Correspondence: mario.testini@uniba.it

${ }^{1}$ Unit of Endocrine, Digestive, and Emergency Surgery, Department of Biomedical Sciences and Human Oncology, University Medical School "Aldo Moro" of Bari, Bari, Italy

Full list of author information is available at the end of the article
}

hypertension. Posterolateral hernias (Bochdalek hernias) are the most common hernia type $(>80 \%)$ with the majority occurring on the left side (85\%), less frequently on the right side (13\%) or bilateral (2\%) [2].

Diaphragmatic rupture (DR) is an infrequent complication of trauma that occurs during $5 \%$ of trauma, including vehicle accidents [3-5]. Diagnosis is usually delayed; patients may be asymptomatic for years after trauma, until complications occur. Traumatic rupture of the diaphragm is considered an indication for surgical repair, especially in symptomatic patients [6].

However, there is no consensus on the absolute indications to surgery and about the timing. The onset of complications carries highest mortality and morbidity rates; therefore, it makes emergency surgery mandatory. During the past decades, primary suture repair or covering the defect with a synthetic mesh has been the 
standard procedures. More recently, biologic meshes have been thought to be effective in closing the diaphragmatic defect, inducing limited inflammatory response and minimizing adhesion formation [7]. Laparotomy or thoracotomy are the traditional treatments for patients with DR. Moreover, laparoscopic approaches for repair of hernias have recently gained in popularity [8]. Robotic approach is not yet described as effective approach in emergency, and it is reported in literature in only one case [9] in elective surgery.

This paper includes the surgical experience of congenital or traumatic diaphragmatic hernia of a surgical unit in emergency setting and reports the literature.

\section{Methods}

Six cases of diaphragmatic hernia were observed in emergency at our Academic Department, with respiratory and abdominal symptoms. No breath sounds were detected in the left chest area, but bowel sounds were audible. Emergency surgery was performed in all cases. The hernia contents were reduced, and the defect was closed with primary repair or mesh.

Case 1: A 63-year-old woman was admitted with complaints of bowel obstruction and dyspnoea. Anamnesis revealed chronic abdominal pain, mental retardation and strabismus. In the physical examination, no breath sounds were detected in the left chest area; however, bowel sounds were audible. Chest X-ray and barium enema showed the transverse colon displaced into the left hemithorax above the splenic flexure. Computed tomography suggested collapse of the lung and the mediastinal shift towards the right. The left diaphragmatic hernia contained the transverse and descending colon (Fig. 1a). Emergency laparotomy was performed, and a left diaphragm agenesis, mega colon (diameter $10 \mathrm{~cm}$ ) and left liver agenesis were found. An intra-operative bronchoscopy revealed hypoplasia of the left lung (Fig. 1b). A subtotal colectomy with ileo-rectal anastomosis was performed, and primary repair of diaphragm was done. The post-operative course was uneventful, and the patient was discharged on the 15th postoperative day. The research of abnormalities of the karyotype, phenotype and genetic pattern was negative for all the known congenital syndromes.

Case 2: A 50-year-old woman was admitted with complaints of dyspnoea, chest and abdominal pain. No breath sounds were detected in the left chest area. There was no history of trauma. Chest X-ray revealed mediastinal shift towards the right and bowel gas in the left chest. CT scan showed large annular diaphragmatic defect which allowed passage of the stomach, spleen and colon (Fig. 2). An emergency combined chest-abdominal approach was performed, and contents were reduced repairing the defect with Mersilene mesh . Thoracotomy approach was used to release the thoracic dense adhesion between the chest and the abdominal contents. Before placing the mesh, the anaesthesiologist increased the tidal volume to expand the collapsed left lower lobe of the lung and a chest drain was placed in the left pleural space. Immediate post-operative chest X-ray showed expansion of the left lung with minimal pleural effusion. Post-operative course was uneventful, and postoperative stay was 13 days.

Case 3: A 73-year-old woman arrived with complaint of breathlessness and dysphagia. No history of trauma was evident in anamnesis. Her current medical history included hypertension and hypothyroidism. Chest X-ray and barium studies demonstrated the presence of stomach in left hemithorax. CT scan revealed the presence of large diaphragmatic hernia which allowed the stomach

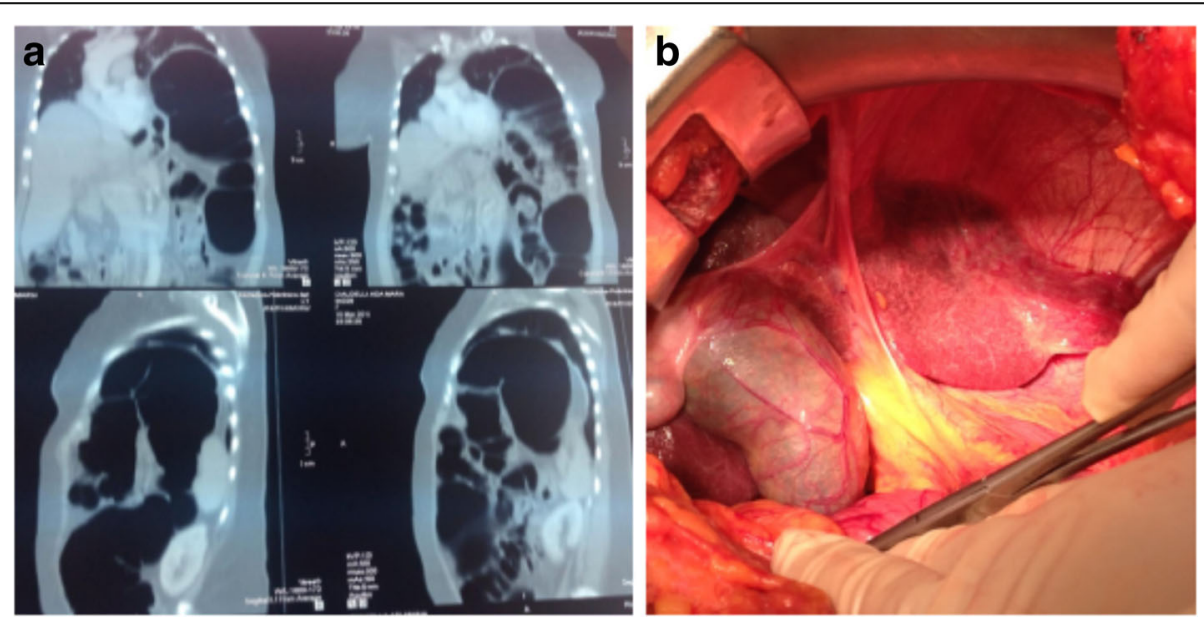

Fig. 1 a CT scan shows collapse of the lung and the mediastinal shift towards to the right side. The left diaphragmatic hernia contained the transverse and descending colon. $\mathbf{b}$ Intraoperative evidence: diaphragmatic defect allows migration of viscera 


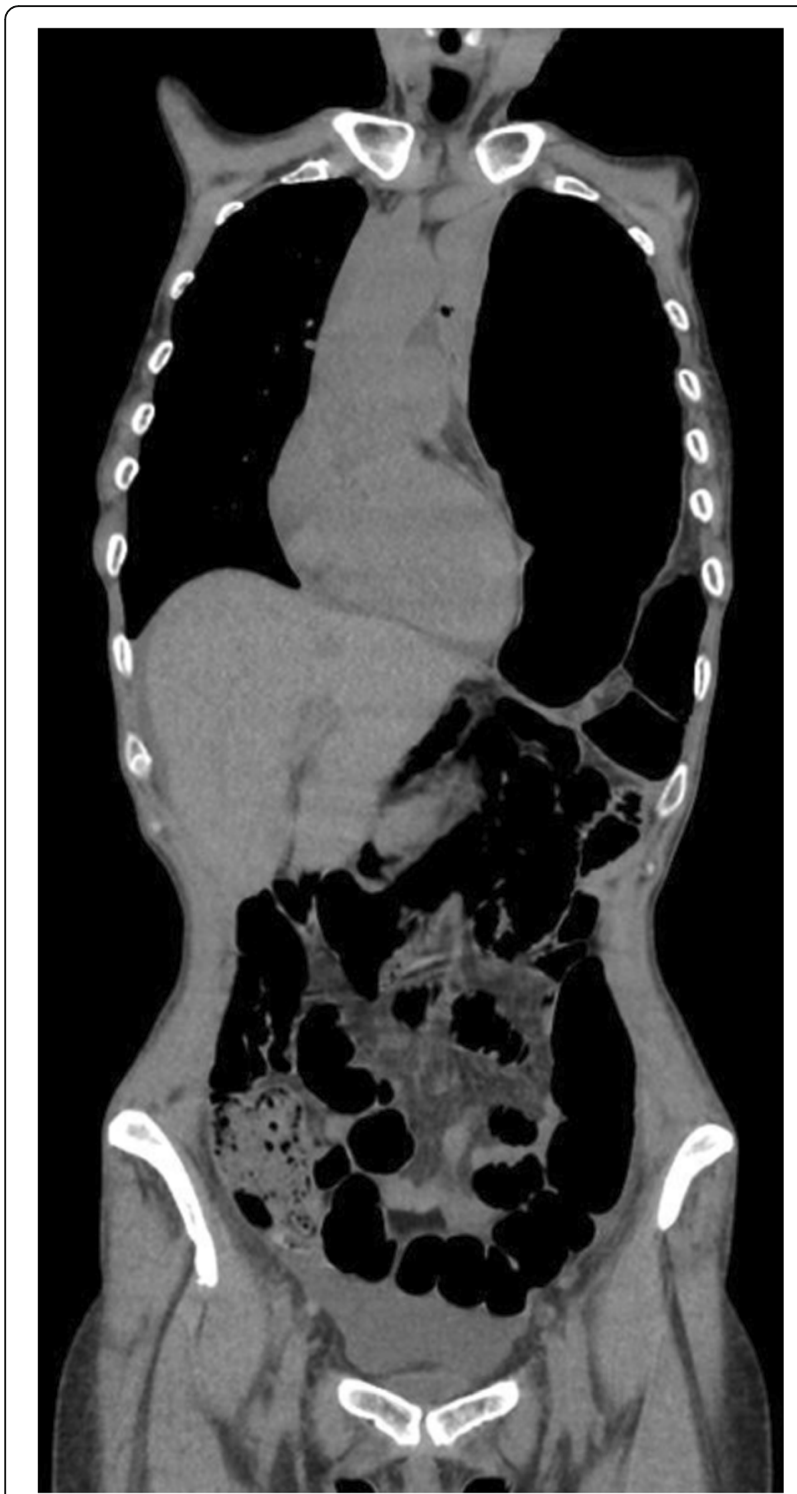

Fig. 2 CT scan shows in left side, large diaphragmatic defect which allows passage of the stomach, spleen and colon (referred to as Bochdalek hernias) and complete collapse of left lung

to herniate into the chest. Emergency laparoscopy was performed; hernia contents were reduced; and a repair of the defect with Proceed mesh was done (Fig. 3). The post-operative course was uneventful, and patient was discharged 7 days after surgery.

Case 4: A 63-year-old woman was admitted with complaints of breathlessness for 2 days, which was gradually progressive and associated with left-sided chest pain and a dry cough. There was a history of a vehicle accident 6 years ago. The initial chest radiograph revealed an elevated left hemi diaphragm with presence of a colon gas shadow in the lower half of the hemithorax. CT scan suggested left diaphragmatic hernia which allowed passage of the spleen, left lobe of liver and transverse colon
(Fig. 4a). Surgery was performed in emergency, reducing contents and repairing the defect with biological mesh (Fig. 4b; Tutomesh, bovine pericardium mesh). The patient was discharged on the $10^{\text {th }}$ post-operative day, without complications.

Case 5: A 50-year-old man was involved in a work accident. He was managed in accordance with Advanced Trauma Life Support protocol. He arrived in the emergency room with decreased breath sounds on the left side, dyspnoea, fever, left hypochondrium hematoma, subcutaneous emphysema, and chest and abdominal pain. His current medical history included obesity and treated hypertension. Initial chest radiography and barium studies demonstrated stomach in the left hemithorax. CT scan revealed stomach and spleen in left hemithorax, consistent with a traumatic diaphragmatic rupture with complete disruption of all muscular layers, collar sign and multiple rib fractures, fractured left humerus and scapula (Fig. 5a, b). At exploratory laparotomy, traumatic defect in the left diaphragm was found, with stomach and spleen in the left thorax (Fig. 5c). The hernia contents were reduced and the defect was closed with biologic mesh (Tutomesh bovine pericardium mesh). Post-operatively, the patient was placed in an intensive care unit. He was transferred from the ICU on the 8th post-operative day and discharged on the 20th day.

Case 6 [10]: A 51-year-old man, referred to a history of 5 months of dyspnea, abdominal pain, nausea and vomiting. These symptoms had increased in severity during the previous 2 weeks. Anamnesis revealed left splenopancreatectomy 4 years earlier for non-Hodgkin's lymphoma. The physical examination revealed a moderate peritoneal effusion without a peritoneal reaction. The introduction of a nasogastric tube remarkably improved symptoms. The chest X-ray showed a large fluid level beneath an apparently raised left hemi diaphragm (Fig. 6a) hypothesizing a left hemi diaphragmatic rupture with gastric herniation; diagnosis was confirmed by barium studies and a thoracic-abdominal computed tomography. An emergency left thoracotomy was performed, revealing a volvulus of the stomach, with some intestinal loops. Part of the transverse colon was incarcerated herniating through the torn diaphragm. The hernia was localized into the posterior side of the left hemi diaphragm with a diameter of $12 \mathrm{~cm}$. During surgery, dense adhesions between the herniated organs and the left pleura-lung, as well as a marked reduction in left lung volume and an inflammatory mass in the greater omentum adherent to the diaphragm, were found. Thus, a reduction of the volvulus, an adhesiolysis and a resection of the mass were performed. Finally, a direct suture of the left diaphragmatic defect was employed (Fig. 6b, c). The patient had an uneventful recovery and histology showed Hodgki's lymphoma. 


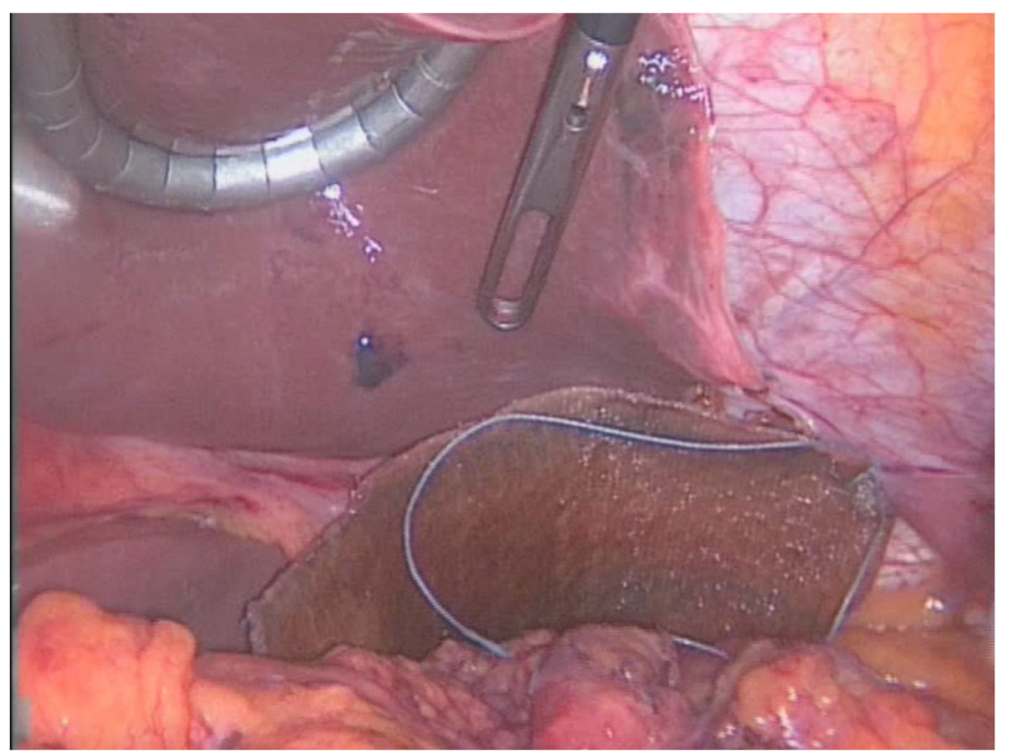

Fig. 3 Laparoscopic image during correction of defect with synthetic mesh

\section{Review of the literature}

A systematic review was performed by consulting PubMed/MEDLINE from 1983 to 2017 using the terms "emergency surgery", associated with "traumatic diaphragmatic rupture", and "congenital diaphragmatic hernia”. The search returned 555 papers (Fig. 7). Three hundred twenty-three publications were excluded because these articles were not written in English $(N=87)$, presented cases in childhood ( $<19$ years old; $N=178$ ) or were not interesting human species $(N=58)$; 32 papers were excluded because regarded hiatal hernia, 40 paraesophageal hernia and 59 elective setting. Consequently, the full texts of 101 articles were assessed for eligibility: the ethiopathogenesis was traumatic in 697 patients and congenital in 38 (Table 1).

\section{Pathogenetic mechanism}

Diaphragmatic rupture with abdominal organ herniation was first described in 1541 by Sennertus [11]. Congenital diaphragmatic hernias are prenatally or during the neonatal period diagnosed. On the contrary, $\mathrm{CDH}$ in adulthood are exceedingly rare and can occur through an anterior parasternal Morgagni foramen or through a posterolateral, mainly left-sided, named as Bochdalek hernia, firstly described in 1848 [12]. The aetiology is still under study, but the disease is due to the failure of closure of the canal between the septum transversum and the oesophagus during the 8th week of gestation. Morgagni hernia is a rare disease caused by the defective development of the sternal attachments to the diaphragm. Traumatic diaphragmatic hernias are thought to be produced by a sudden increase in the pleuroperitoneal pressure gradient occurring at areas of potential weakness along embryological points of fusion [13].

DR usually result from blunt or penetrating injuries or iatrogenic causes and result in entry of an abdominal hollow viscus or the omentum into the pleural cavity, which may lead to incarceration and even strangulation with a fatal outcome. Traumatic diaphragmatic hernias are frequently caused by a penetrating injury (10-19\%), sometimes by blunt thoracic-abdominal trauma (5\%) $[14,15]$. Moreover, some authors described rare and particularly cases of DR after surgery or pregnancy; that is Sano A. et al. reported a case of a pregnant woman in the 28th week of pregnancy, who was underwent to emergency caesarean section and repair of the diaphragm [16]; Moussa G. et al., described a right DR in a patient with previous history of window fenestration and sarcoidosis [17]; Nakamura T. et al., reported a case of right DR in patient with a history of hepatic carcinoma treated with radiofrequency ablation [18]. Furthermore, there was an association between Marfan's syndrome and $\mathrm{CDH}$ as Barakat et al. reported [19].

\section{Site of rupture}

$\mathrm{CDH}$ formation is found $80 \%$ on the left side [20]. Also, $88-95 \%$ of diaphragmatic ruptures occurred on the left side [21], especially, blunt trauma causes large diaphragmatic defects, commonly involving $(>80 \%)$ the left posterolateral diaphragm [22]. The right haemidiaphragm is stronger than the left one because of the size of the liver which has a protective effect. For this reason, the side ruptures are very rare and associated with high mortality and morbidity rate [23]. 

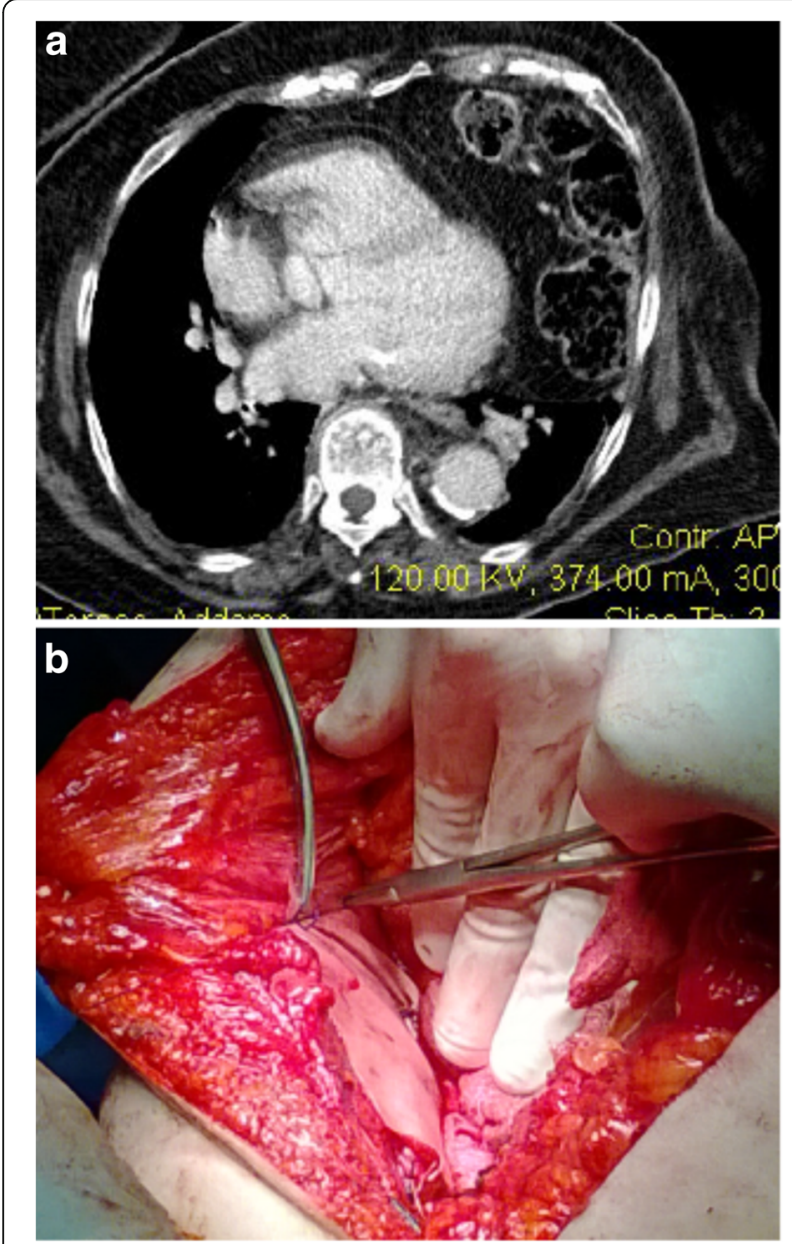

Fig. 4 a CT scan suggests left diaphragmatic hernia which allowed migration of colon in left chest. $\mathbf{b}$ Intraoperatively, biological mesh repairing defect

The review of literature reported in this study confirmed the high frequency of left defect $80 \%$, and only two cases of bilateral DR were reported.

\section{Presenting symptom and investigations}

Nayak et al. described severe symptoms, in $46 \%$ of CDH cases with $32 \%$ of mortality due to visceral strangulation [24]. Moreover, the literature analysis shows a variable rate of delayed symptoms $(5-45.5 \%)[25,26]$. Latepresenting $\mathrm{CDH}$ of left sided typically produces acute, obstructive, gastrointestinal symptoms, chronic dyspnea, chest pain, recurrent abdominal pain, postprandial fullness and vomiting, evolving to cardiorespiratory failure [27]. Indeed, right-sided CDH is usually associated with only respiratory issues because partial liver displacement may block the further herniation of hollow viscera [1]. Although the presence of bowel sounds within the chest and the absence of breath sounds are typical findings associated with a $\mathrm{CDH}$, a misdiagnosis rate of $38 \%$ has
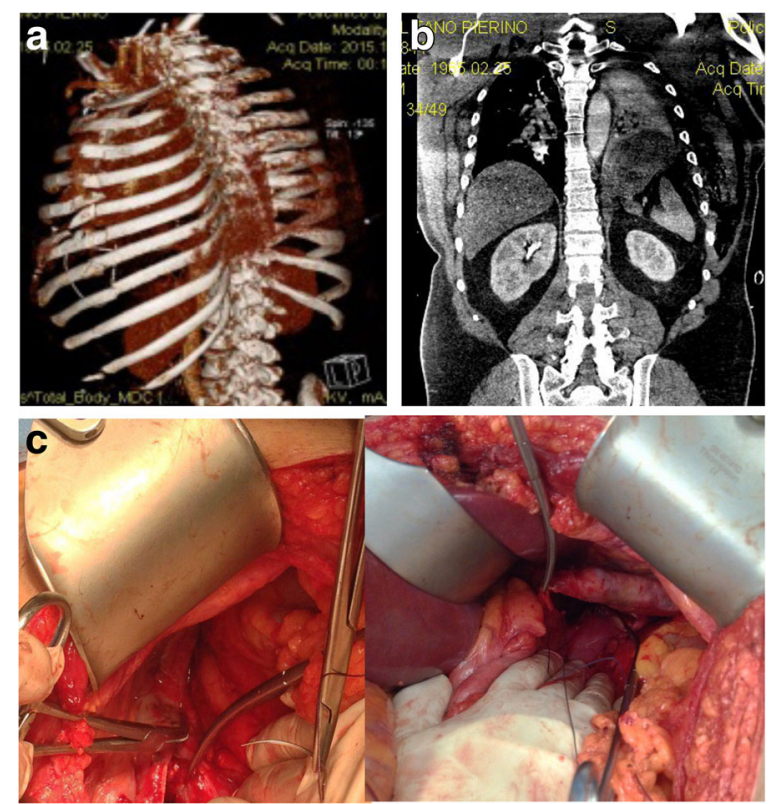

Fig. 5 a 3D-CT scan shows rib fractures. b CT scan shows stomach and spleen in the left hemi-thorax, complete disruption of all muscular layers. c Intraoperatively, repair of traumatic defect in the left diaphragm

been reported [28]. Obviously, in totally asymptomatic cases, diagnosis is very hard. On the contrary, when acute presentations occur because of the increasing of abdominal pressure and consequent rapid visceral displacement into the chest or due to rapid distension of previously herniated viscera, diagnosis is clear $[29,30]$.

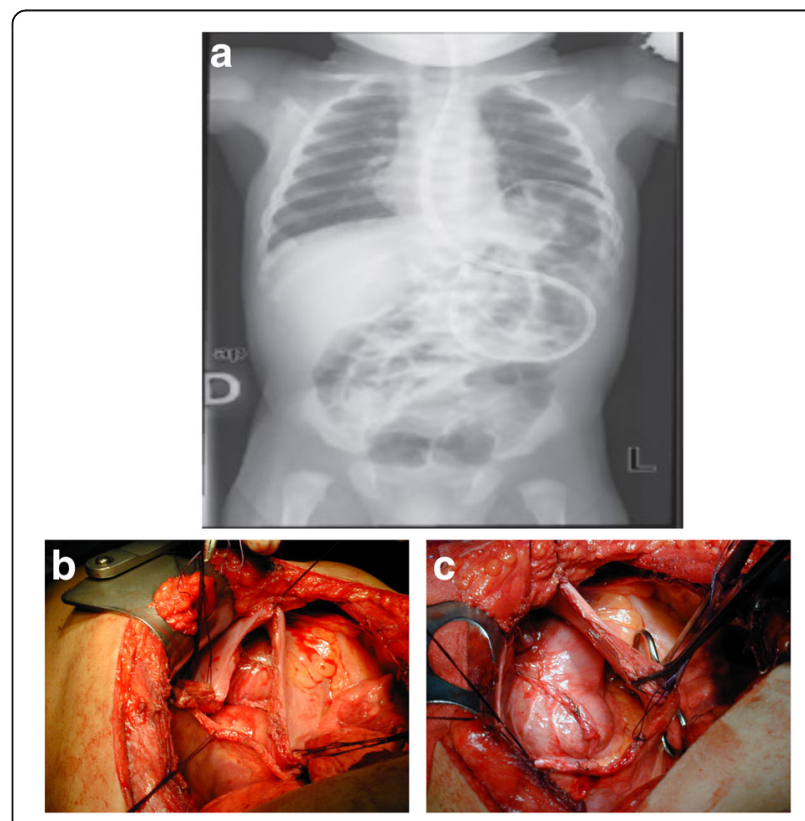

Fig. $\mathbf{6}$ a X-ray shows herniated stomach into the chest. b Thoracotomy shows large diaphragmatic defect. c Repair of defect 
First research performed for "emergency surgery" associated with "traumatic diaphragmatic rupture", "congenital diaphragmatic hernia" - 555 publications

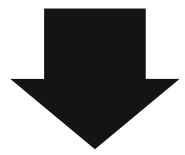

Papers excluded (323)

- Article not in English (87)

- Age<19 (178)

- No human species (58)

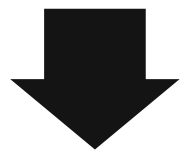

232 publications

Other papers excluded (131)

- hiatal hernia (32)

- paraesophageal hernia (40)

- Others (59)

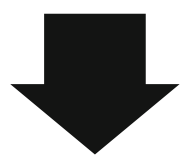

Papers identified for review (101) which described:

735 cases

- 697 cases of traumatic DH

- 38 cases of congenital DH

Fig. 7 Flow chart of the literature selection process
Chest X-ray and barium studies are useful for determining which viscera have herniated into the thorax. The most common reported radiological finding of $\mathrm{CDH}$ is the opaqueness of the hemithorax usually associated with mediastinal shift to the contralateral side. Moreover, the position of the nasogastric tube in the chest cavity will provide an important indicator and prompt correct diagnosis. Computed tomography can be considered the gold standard technique for diagnosis, offering the unique opportunity to evaluate the presence, size and location of a diaphragmatic defect, as well as the contents of various types of diaphragmatic hernias [31] and showing sensitivity and specificity of $14-82 \%$ and $87 \%$, respectively [32]. MRI is also useful, but usually it is not performable in emergency. However, it is usually employed in stable patients or where the CT scan is equivocal [33]. According with literature, in this reported experience, a definitive diagnosis was made with CT scan and barium studies.

Late-presenting $\mathrm{CDH}$ is considered as a benign condition but it can rapidly becomes a life-threatening disease [1, 27, 28, 31, 33]; consequently, an immediate surgical treatment is mandatory. Associated anomalies in latepresenting $\mathrm{CDH}$ patients, such as congenital heart disease, Fryns syndrome and trisomy 18, have been reported in $8.6-80 \%$ of cases [1, 2, 27, 28], significantly increasing the mortality rate. At this proposal, in case 1 , even if there was a high suspicion of congenital syndrome, surprisingly it was not confirmed by genetic studies.

\section{Surgical treatment}

Surgical repair typically involves primary or patch closure of the diaphragm through an open abdominal approach. When the diagnosis is delayed, due to suspicions of adhesions between viscera and chest, thoracotomy or combined thoracic-abdominal approach is preferred, as in the reported case 2. Some authors have reported success with thoracoscopic approach but vitiated by an increased incidence of hernia recurrence [34-36]. Furthermore, during thoracoscopy, an intraoperative pulmonary hypertension with subsequent hemodynamic instability could develop; moreover, the placement and management of a patch results in substantially longer operating times. For these reasons, thoracoscopic repair of $\mathrm{CDH}$ is preferred in the presence of small diaphragmatic defects and/or mild pulmonary hypertension [37]. Nowadays, the laparoscopic approach is safe and feasible for $\mathrm{CDH}$ and it could be an excellent option [37], as in case 3.

However, emergency surgery is the treatment of choice for diaphragmatic rupture. In delayed cases, thoracic approach is recommended to reduce viscera-pleural adhesions and to avoid intra-thoracic visceral perforation 


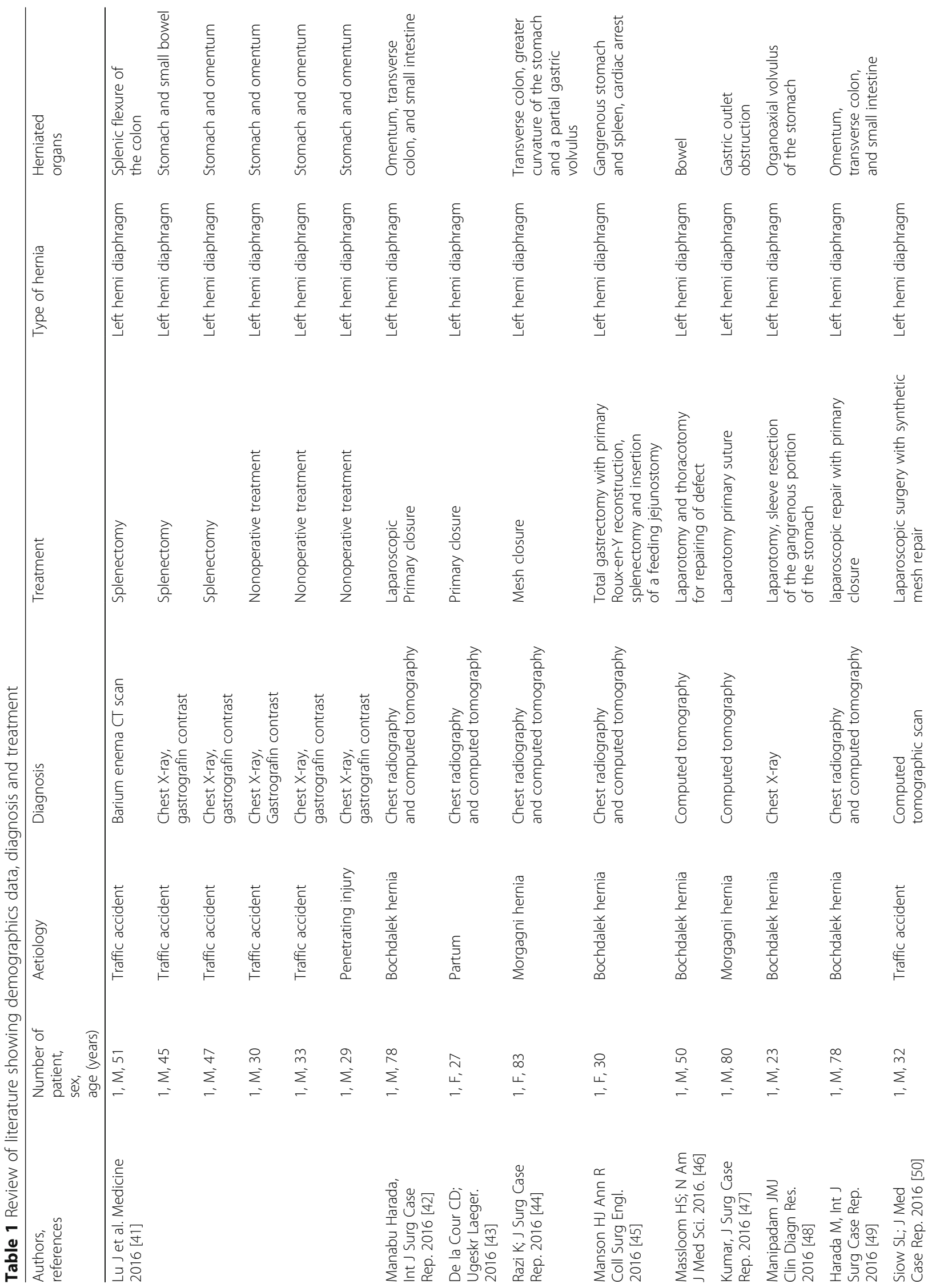




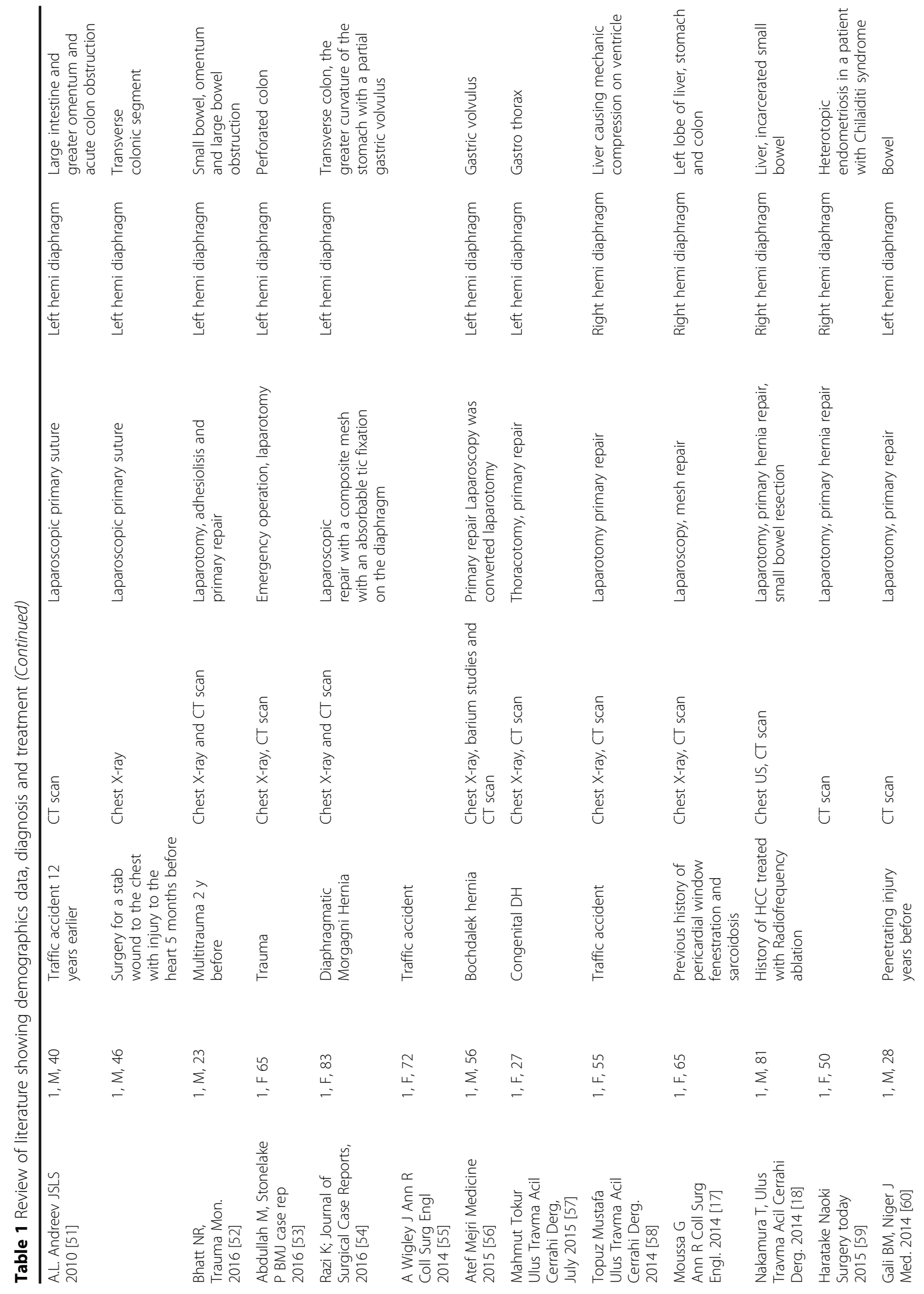



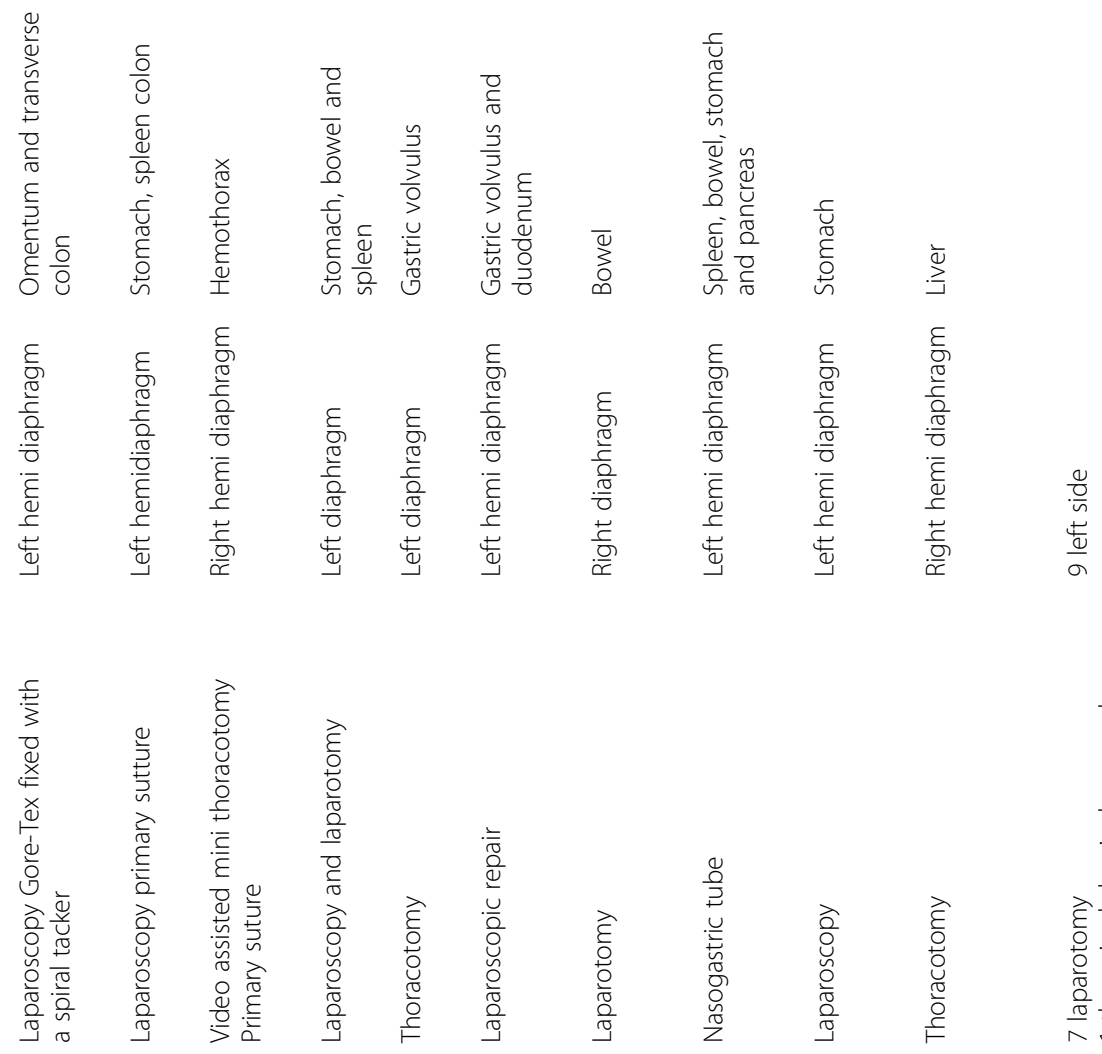

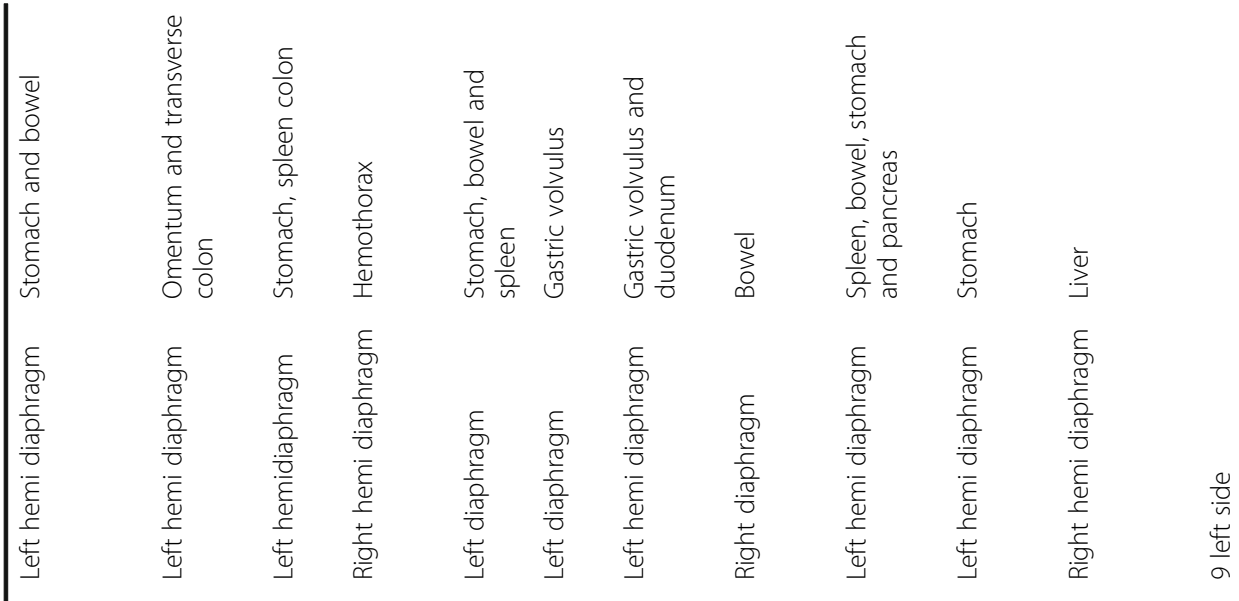

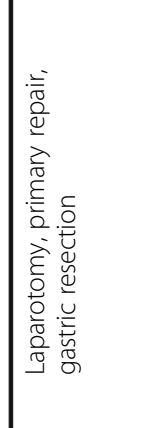

$\begin{array}{llll}0 & 0 & 0 \\ 0 & 0 & 0 & 0\end{array}$

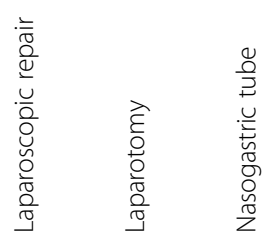
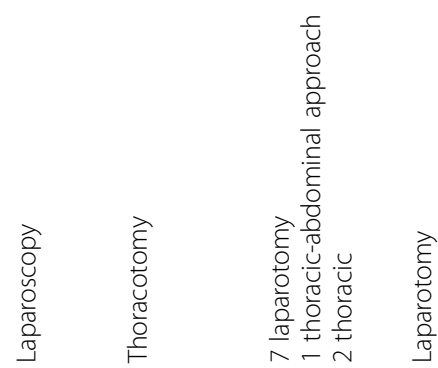

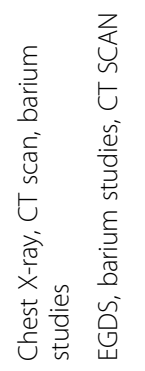

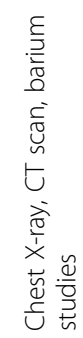

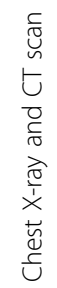

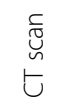

$\frac{\widetilde{\Xi}}{\longleftarrow}$

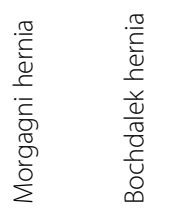<smiles>CC#COC(C)C</smiles>

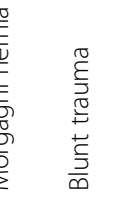

$\overline{0}$
$\overline{0}$
0
$\overline{0}$
$\stackrel{\bar{\Xi}}{\Xi}$

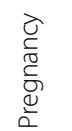

$\frac{\stackrel{+}{0}}{\frac{0}{0}}$

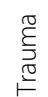

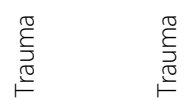

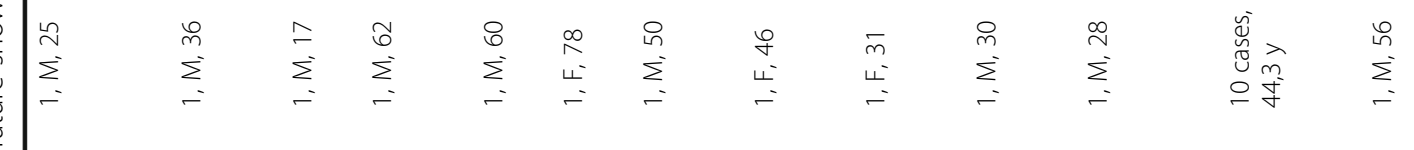

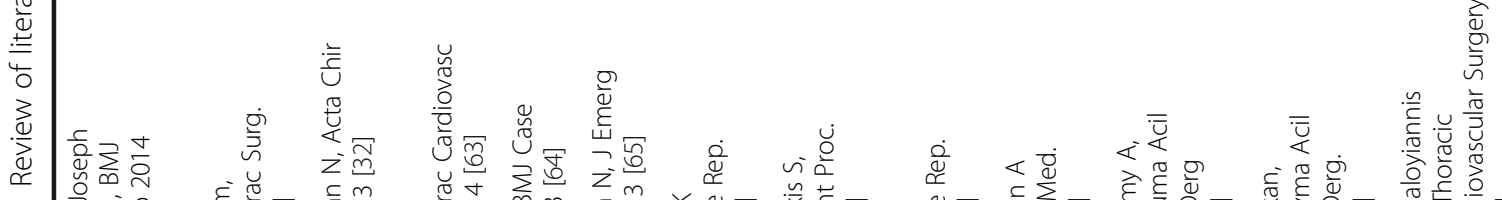

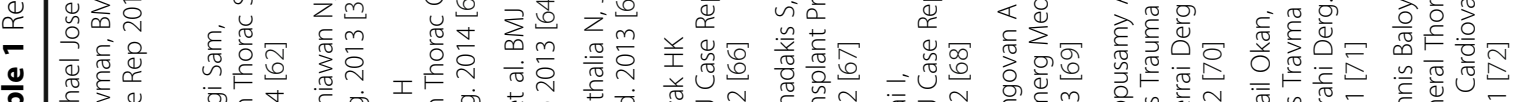

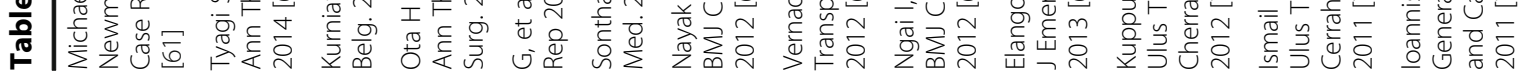




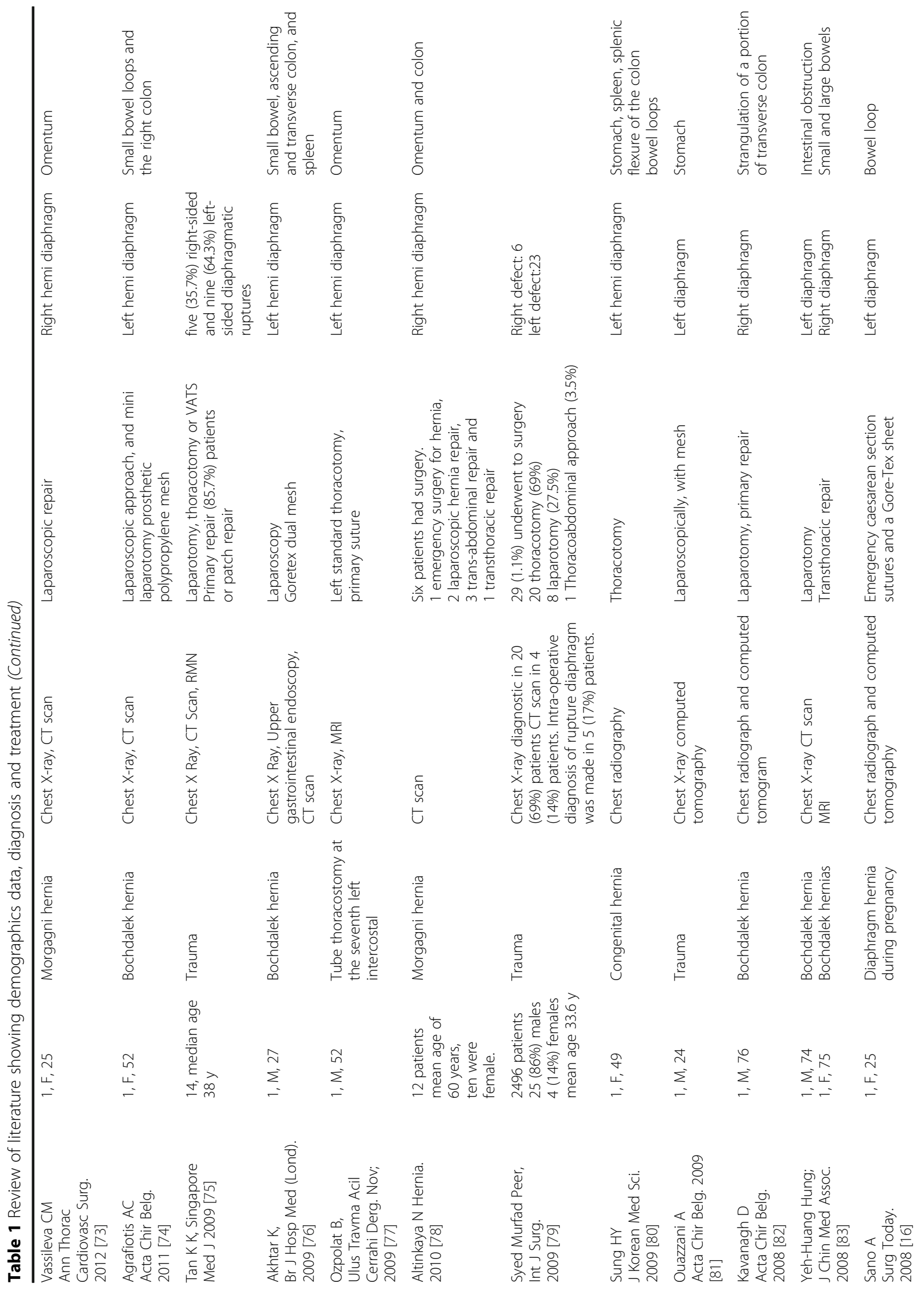




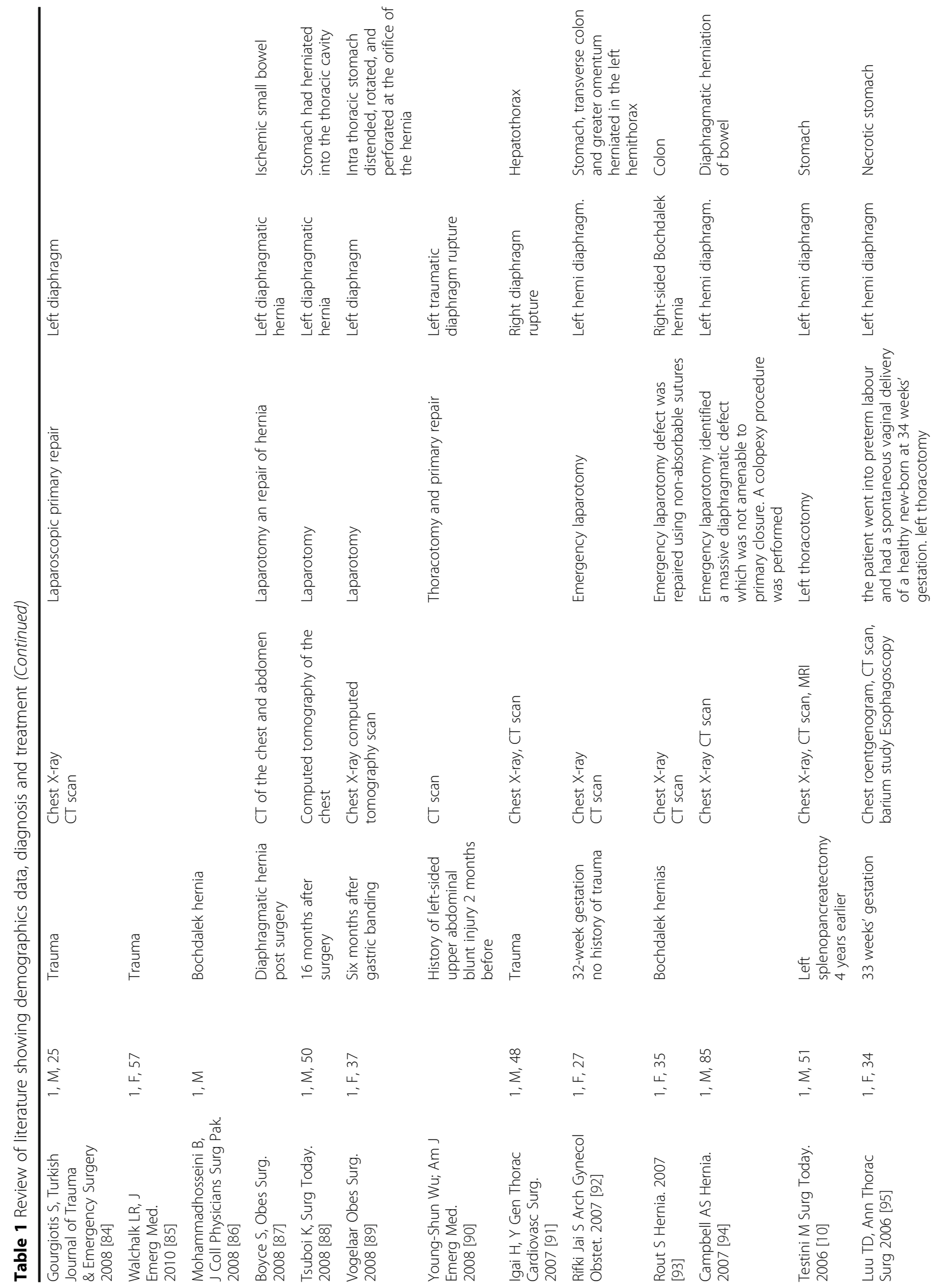




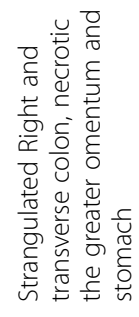

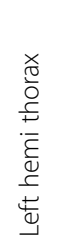
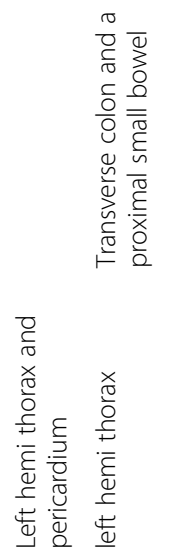

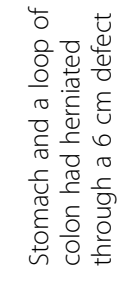

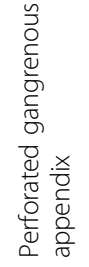
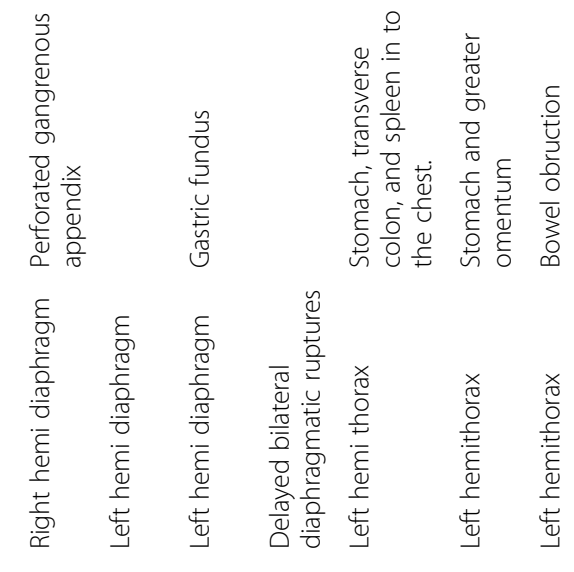

\begin{tabular}{l}
$\varepsilon$ \\
$\frac{0}{0}$ \\
$\frac{0}{2}$ \\
$\frac{0}{0}$ \\
$\frac{0}{0}$ \\
$\frac{0}{9}$ \\
\hline
\end{tabular}

हो.

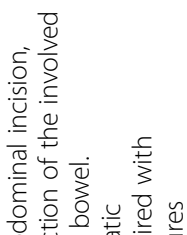

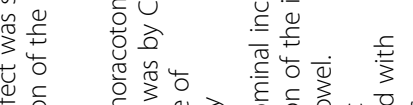

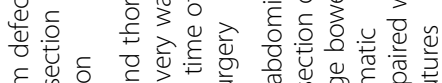

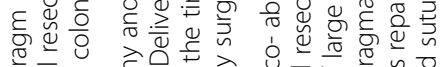

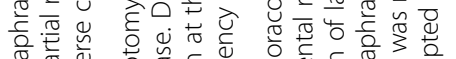

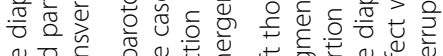

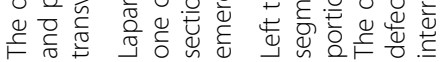

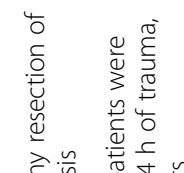

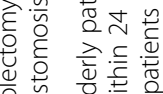

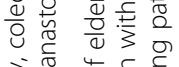

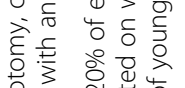

离

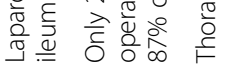
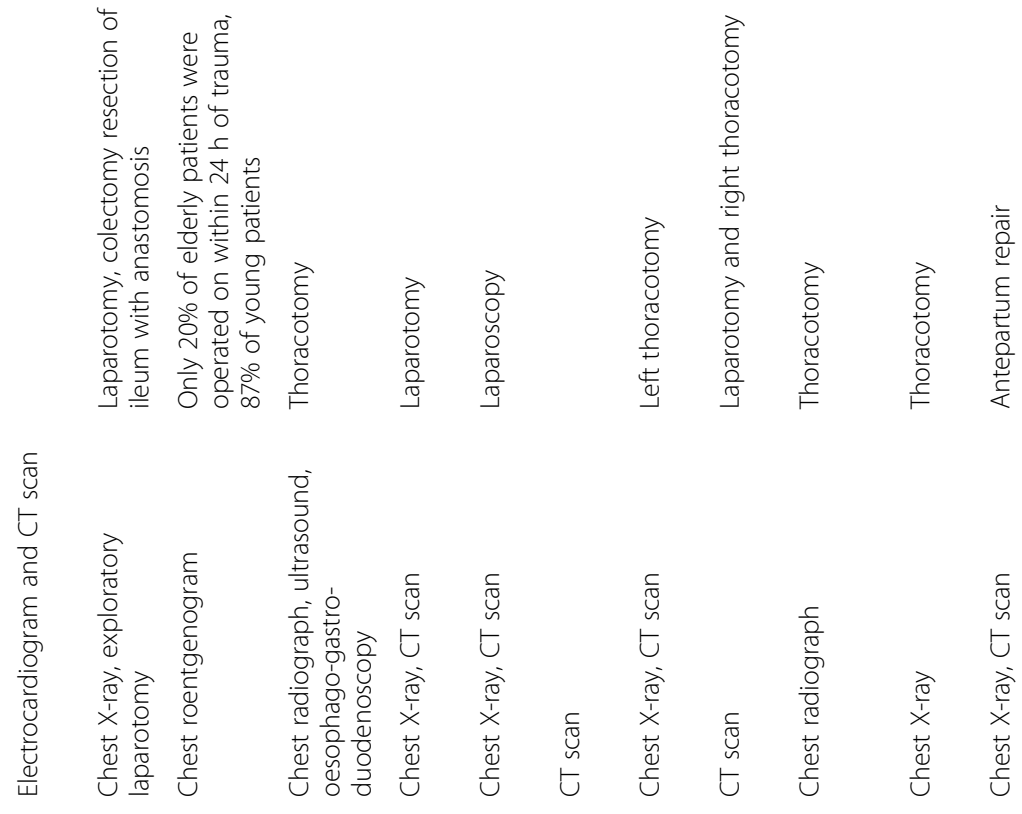

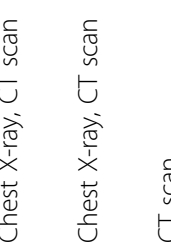

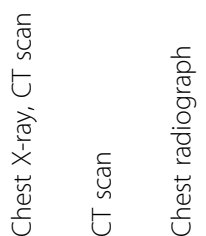

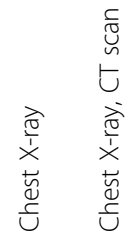

ฆे
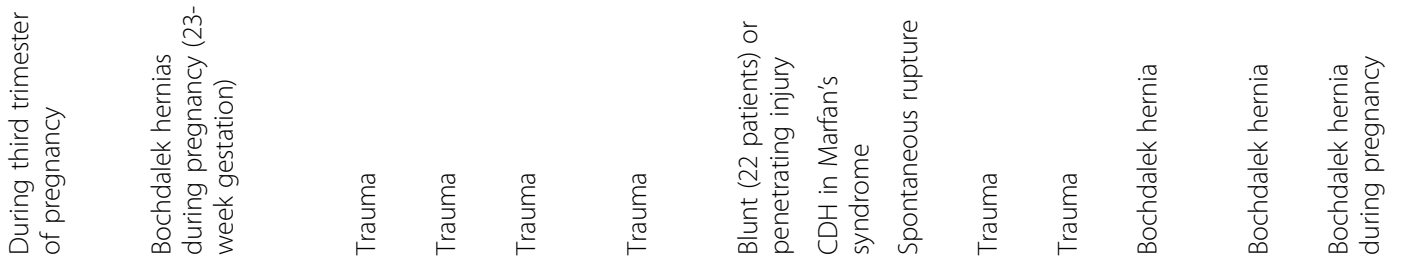

$\begin{array}{lll}\overline{0} & \bar{m} & \bar{m} \\ \stackrel{0}{L} & \mathbb{5} & \stackrel{5}{=} \\ = & m & \end{array}$

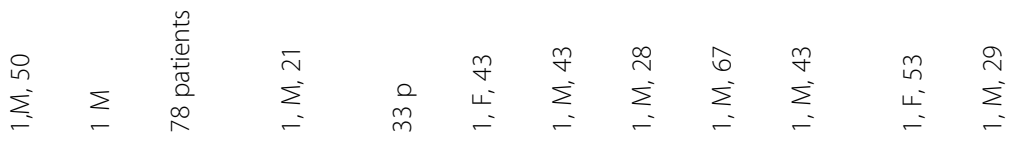

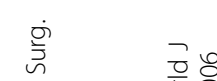

읗

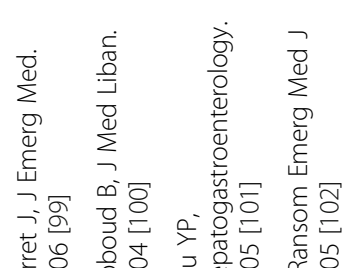

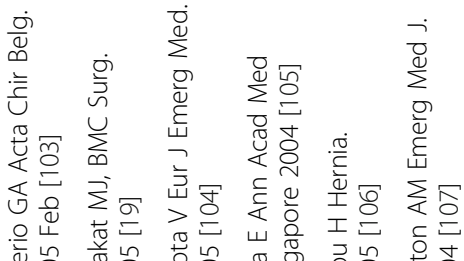

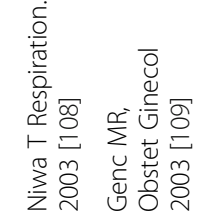




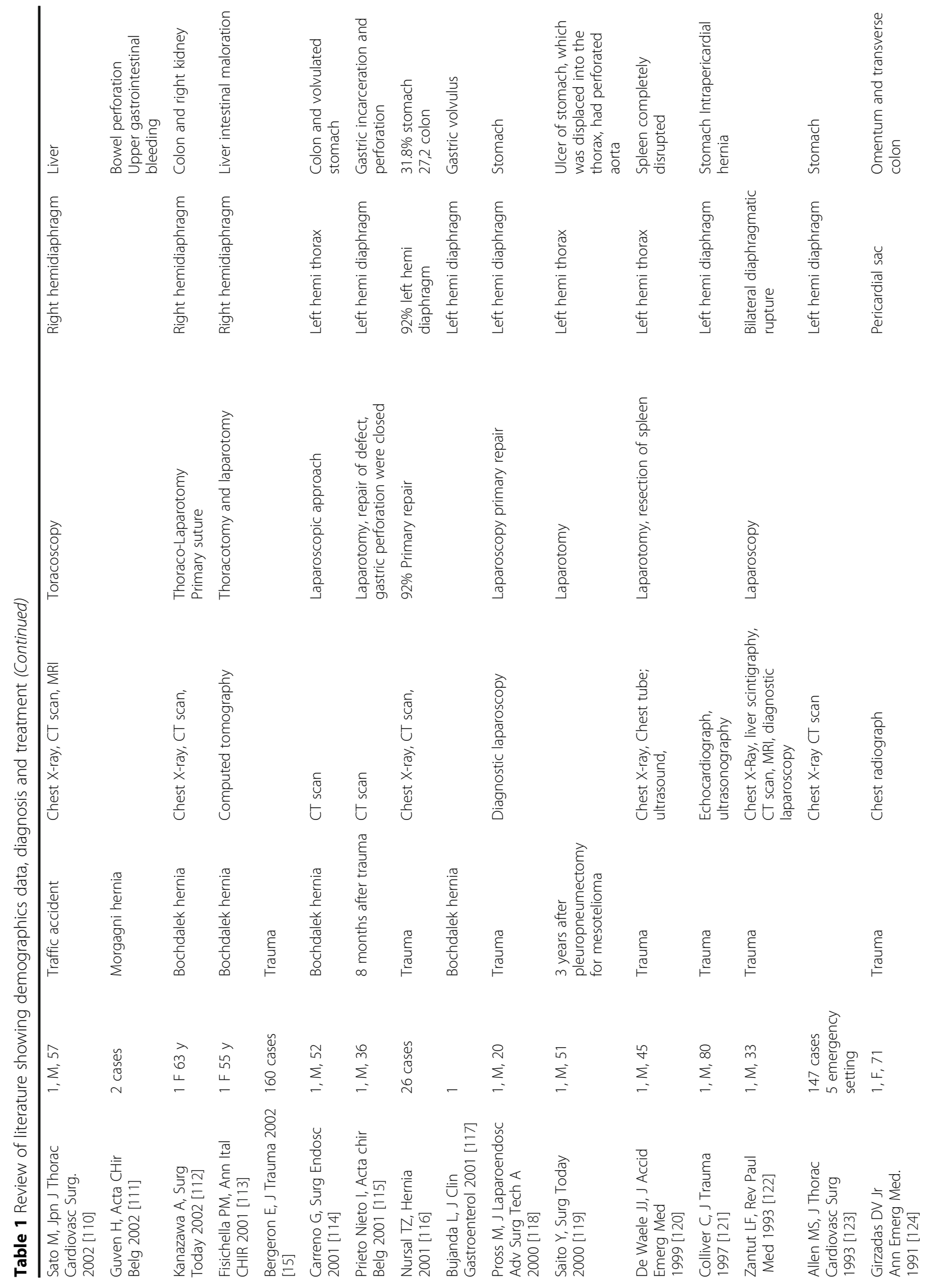




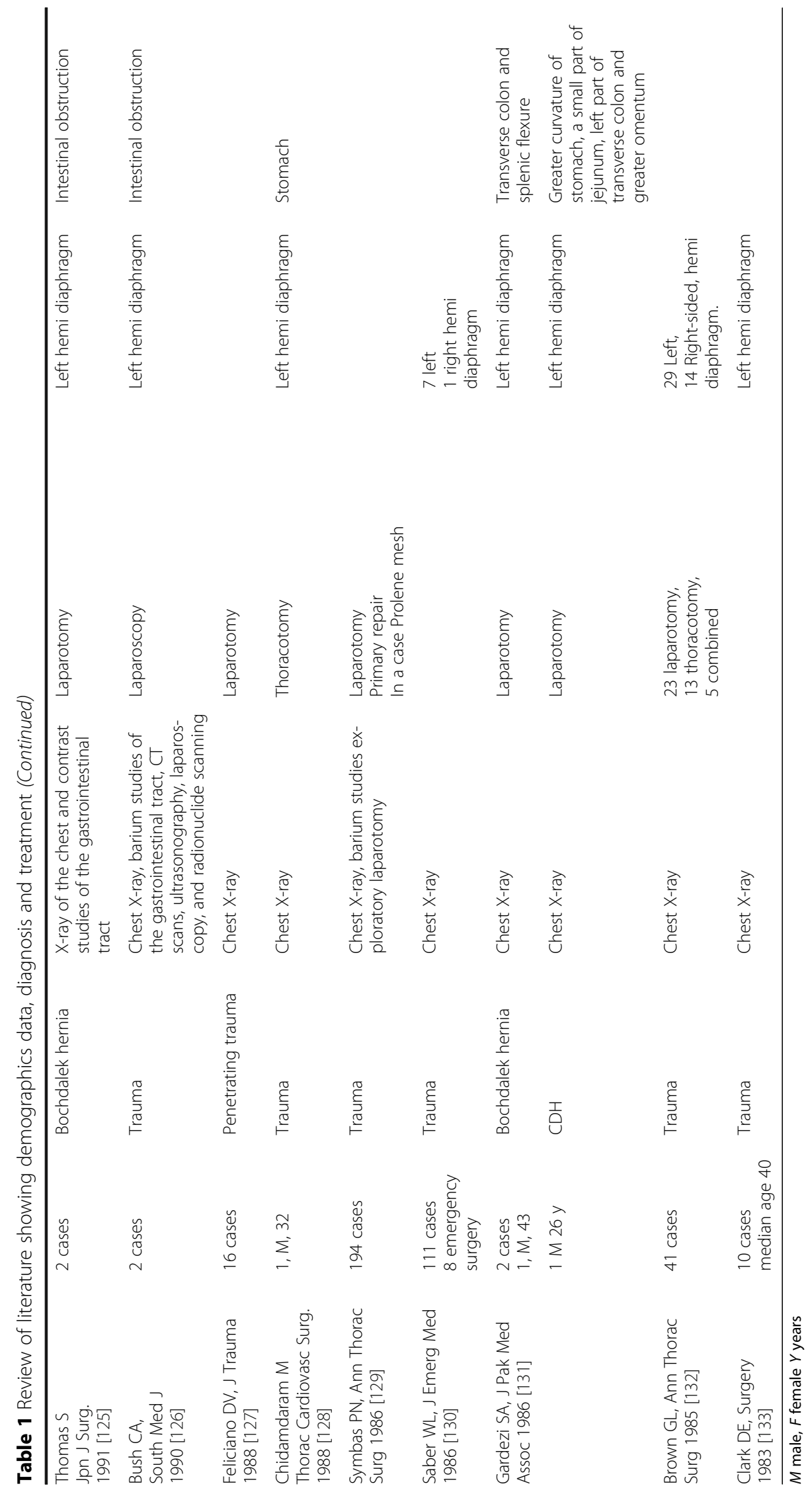


with catastrophic complications [38]. When the suspicion of intestinal obstruction is evident, an abdominal approach may also be required to control organs. Although the type of closure used for diaphragmatic hernias is still a matter of debate, it is generally accepted that most defects can be primarily closed with a nonabsorbable suture [39]. Mesh repair usually is used when the defect is too large to be primarily closed and the use of tension free mesh is vital to the success of the procedures. Recently, biologic mesh has been introduced to replace the synthetic one because of its lower rate of hernia recurrence, higher resistance to infections and lower risk of displacement $[7,40]$; however, limited evidence in literature yet exists about their superiority. Indeed, in our previous experience, biologic meshes have also been used in contaminated surgical fields with favourable results [40]. However, because of the rarity of this condition, clinicians should be encouraged to publish their experience with biologic meshes in diaphragmatic hernia repair [7].

\section{Conclusions}

When a diaphragmatic hernia is diagnosed, surgery is the treatment of choice, above all in emergency setting. A multidisciplinary approach in dedicated centres is advisable.

\section{Abbreviations}

$\mathrm{CDH}$ : Congenital diaphragmatic hernia; $\mathrm{CT}$ : Computed tomography; DR: Diaphragmatic rupture; MRI: Magnetic resonance imaging

\section{Acknowledgements}

The authors would like to thank Dr Channielle Mascarenhas and Dr Luke Palma for the English language revision.

\section{Funding}

This study did not receive funding.

\section{Availability of data and materials}

All data and materials are available in case of request.

\begin{abstract}
Authors' contributions
Authors contributed to this study as follows: MT contributed to the conception and design. AG contributed to the writing acquisition of the data. RMI contributed to writing. GC and AD contributed to the critical revision. AP contributed to the review of literature. AG contributed to the conception and design and critical revision. All authors read and approved the final manuscript.
\end{abstract}

\section{Competing interests}

The authors declare that they have no competing interests.

\section{Ethics approval and consent to participate}

Ethics approval and consent was waived because this study is a review of literature with a retrospective case series based on six patients that gave consent to participate for publication.

\section{Publisher's Note}

Springer Nature remains neutral with regard to jurisdictional claims in published maps and institutional affiliations.

\section{Author details}

'Unit of Endocrine, Digestive, and Emergency Surgery, Department of Biomedical Sciences and Human Oncology, University Medical School "Aldo Moro" of Bari, Bari, Italy. 'Department of Thoracic Surgery, University of Bari, Bari, Italy. ${ }^{3}$ Unit of Laparoscopic Surgery, Department of Emergency and Organ Transplantation, University Medical School "A. Moro" of Bari, Bari, Italy.

Received: 14 March 2017 Accepted: 9 May 2017

Published online: 18 May 2017

\section{References}

1. Baerg J, Kanthimathinathan V, Gollin G. Late-presenting congenital diaphragmatic hernia: diagnostic pitfalls and outcome. Hernia. 2012;16:461-6.

2. Torfs CP, Curry CJ, Bateson TF, Honoré LH. A population-based study of congenital diaphragmatic hernia. Teratology. 1992;46:555-65.

3. Pancholi CK, Hombalkar NN, Dalvi SB, Gurav PDY. Left sided hydropneumothorax in a operated case of left diaphragmatic hernia repair: a diagnostic dilemma. J Clin Diagn Res. 2015;9:PD03-4.

4. Meyers BF, McCabe CJ. Traumatic diaphragmatic hernia. Occult marker ofserious injury. Ann Surg. 1993;218:783-90.

5. Kozak $\mathrm{O}$, et al. Late presentation of blunt right diaphragmatic rupture (hepatic hernia). Am J Emerg Med. 2008;26(5):638. e3-5.

6. DeAlwis K, Mitsunaga EM. Sudden death due to nontraumatic diaphragmatic hernia in an adult. Am J Forensic Med Pathol. 2009;30:366-8.

7. Antoniou SA, Rudolph P. The use of biological meshes in diaphragmatic defects an evidence-based review of the literature. In: Frontiers in surgery October 2015. 2015.

8. Izzo BG, Maffettone V, et al. Laparoscopic treatment of Bochdalek hernia without the use of a mesh. Surg Endosc. 2003;17:1497-8.

9. Chen B, Finnerty BM, Schamberg NJ, Watkins AC, DelPizzo J, Zarnegar R. Transabdominal robotic repair of a congenital right diaphragmatic hernia containing an intrathoracic kidney: a case report. J Robot Surg. 2015;9(4): $357-60$.

10. Testini M, Vacca A, Lissidini G, Di Venere B, Gurrado A, Loizzi M. Acute intrathoracic gastric volvulus from a diaphragmatic hernia after left splenopancreatectomy: report of a case. Surg Today. 2006;36(1 1):981-4.

11. Farhan Rashid, Mallicka M Chakrabart, Rajeev Singh and Syed Y Iftikhar. A review on delayed presentation of diaphragmatic rupture. World J Emerg Surg 2009, 4:32 doi:10.1186/1749-7922-4-32

12. Yeh-Huang H, Yu-Hon C, Sheng-Lei Y, Ming-Feng C. Adult Bochdalek hernia with bowel incarceration. J Chin Med Assoc. 2008:71:10.

13. Jing Lu, MDa, Bo Wang, MDb, Xiangming Che, MD, PhDa, Xuqi Li, MDa, Guanglin Qiu, MDa, Shicai He, MDa, Lin Fan, MDa. Delayed traumatic diaphragmatic hernia: a case-series report and literature review. Medicine 2016

14. Mariadason JG, Parsa MH, Ayuyao A, Freeman HP. Management of stab wounds to the thoracoabdominal region. A clinical approach. Ann Surg. 1988;207:335-40.

15. Bergeron E, Clas D, Ratte S, Beauchamp G, Denis R, Evans D, et al. Impact of deferred treatment of blunt diaphragmatic rupture: a 15 -year experience in six trauma centers in Quebec. J Trauma. 2002;52(4):633-40.

16. Sano A, Kato H, Hamatani H, Sakai M, Tanaka N, Inose T, Kimura H, Kuwano $\mathrm{H}$. Diaphragmatic hernia with ischemic bowel obstruction in pregnancy: report of a case. Surg Today. 2008;38(9):836-40.

17. Moussa G, Thomson PM. Bohra A Volvulus of the liver with intrathoracic herniation. Ann R Coll Surg Engl. 2014;96(7):e27-29.

18. Nakamura T, Masuda K, Thethi RS, Sako H, Yoh T, Nakao T, Yoshimura N. Successful surgical rescue of delayed onset diaphragmatic hernia following radiofrequency ablation for hepatocellular carcinoma. Ulus Travma Acil Cerrahi Derg. 2014;20(4):295-9. doi:10.5505/tjtes.2014.03295.

19. Barakat MJ, Vickers JH. Necrotic gangrenous intrathoracic appendix in a marfanoid adult patient: a case report. BMC Surg. 2005;5:4.

20. Brown SR, Horton JD, Trivette $E$, et al. Bochdalek hernia in the adult: demographics, presentation, and surgical management. Hernia. 2011;15: 23-30.

21. Goh BK, Wong AS, Tay KH, Hoe MN. Delayed presentation of a patient with a ruptured diaphragm complicated by gastric incarceration and perforation after apparently minor blunttrauma. Canad J Emerg Med. 2004;6(4):277-80.

22. Ravinder Kaur, Anuj Prabhakar1, Suman Kochhar1, Usha Dalal2 Blunt traumatic diaphragmatic hernia: pictorial review of CT signs. Indian J Rad Imaging / August 2015 / Vol 25 / Issue 3 
23. Kelly J, Condon E, Kirwan W, Redmond H. Post-traumatic tension faecopneumothorax in a young male: case report. World J Emerg Surg. 2008;3:20.

24. Nayak HK, Maurya G, Kapoor N, Kar P. Delayed presentation of congenital diaphragmatic hernia presenting with intrathoracic gastric volvulus: a case report and review. BMJ Case Rep. 2012 Nov 28;2012. pii: bcr2012007332.

25. Kitano Y, Lally KP, Lally PA. Congenital diaphragmatic hernia study group: late presenting congenital diaphragmatic hernia. J Pediatr Surg. 2005;40: 1839-43.

26. Baglaj M. Late-presenting congenital diaphragmatic hernia in children: a clinical spectrum. Pediatr Surg Int. 2004;20:658-69.

27. Hosgor M, Karaca I, Karkiner A, Ucan B, Temir G, Erdag G, et al. Associated malformations in delayed presentation of congenital diaphragmatic hernia. J Pediatr Surg. 2004;39:1073-6.

28. Elhalaby EA, Abo Sikeena MH. Delayed presentation of congenital diaphragmatic hernia. Pediatr Surg Int. 2002;18:480-5.

29. Lawrence B, David S, Sigmund H, Barry S. The late-presenting pediatric bochdalek hernia: a 20-year review. J Ped Surg. 1988;23:735-39.

30. Joel AF, John L, Samuel E, James F, Louis MB. Diaphragmatic hernia masquerading as pneumothorax in two toddlers case report. Ann Emerg Med. 1993:22:1221-4.

31. Chao PH, Chuang JH, Lee SY, Huang HC. Acta Paediatr. 2011;100:425-8.

32. Kurniawan N, Verheyen L, Ceulemans. Acute chest pain while exercising: a case report of Bochdalek hernia in an adolescent. J Acta Chir Belg. 2013; 113(4):290-2.

33. Ravinder Kaur, Anuj Prabhakar1, Suman Kochhar1, Usha Dalal2. Blunt traumatic diaphragmatic hernia: pictorial review of CT signs Indian Journal of Radiology and Imaging / August 2015 / Vol 25 / Issue 3

34. Gander JW, Fisher JC, Gross ER, et al. Early recurrence of congenital diaphragmatic hernia is higher after thoracoscopic than open repair: a single institutional study. J Pediatr Surg. 2011;46(7):1303-8.

35. Lansdale N, Alam S, Losty PD, Jesudason EC. Neonatal endosurgical congenital diaphragmatic hernia repair: a systematic review and metaanalysis. Ann Surg. 2010;252(1):20-6.

36. Tsao K, Lally PA, Lally KP. Minimally invasive repair of congenital diaphragmatic hernia. J Pediatr Surg. 2011;46(6):1158-64.

37. Badillo A, Gingalewski C. Congenital diaphragmatic hernia: treatment and outcomes. Semin Perinatol. 2014;3(8):92-6.

38. Mansour KA. Trauma to the diaphragm. Chest Surg Clin N Am. 1997;7(2): 373-83.

39. Soper NJ, Teitelbaum EN. Laparoscopic paraesophageal hernia repair: current controversies. Surg Laparosc Endosc Percutan Tech. 2013;23(5):442-5.

40. Coccolini F, Agresta F, Bassi A, Catena F, Crovella F, Ferrara R, Gossetti F, Marchi D, Munegato G, Negro P, Piccoli M, Melotti G, Sartelli M, Schianodi Visconte M, Testini M, Bertoli P, Capponi MG, Lotti M, Manfredi R, Pisano M, Poiasina E, Poletti E, Ansaloni L. Italian Biological Prosthesis Work-Group (IBPWG): proposal for a decisional model in using biological prosthesis. World J Emerg Surg. 2012;7:34

41. Lu J, Wang B, Che X, Li X, Qiu G, He S, Fan L. Delayed traumatic diaphragmatic hernia: a case-series report and literature review. Medicine (Baltimore). 2016;95(32):e4362.

42. Manabu H, Harada M, Tsujimoto H, Nagata K, Ito N, Yamazaki K, Kanematsu K, Horiguchi H, Kajiwara Y, Hiraki S, Aosasa S, Yamamoto J, Hase K. Successful laparoscopic repair of an incarcerated Bochdalek hernia associated with increased intra-abdominal pressure during use of blow gun: A case report. Int J Surg Case Rep. 2016;23:131-3.

43. De la Cour CD, Teklay B. Acute post-partum presentation of Bochdalek hernia in a grown-up woman Ugeskr Laeger. 2016 Oct 31;178(44).

44. Razi K1, Light D2, Horgan L. Emergency repair of Morgagni hernia with partial gastric volvulus: our approach. J Surg Case Rep. 2016 Aug 31;2016(8).

45. Manson HJ, Goh YM, Goldsmith P, Scott P, Turner P. Congenital diaphragmatic hernia causing cardiac arrest in a 30-year-old woman. Ann R Coll Surg Engl. 2017;99(2):e75-7.

46. Massloom HS. Acute bowel obstruction in a giant recurrent right Bochdalek's hernia: a report of complication on both sides of the diaphragm. N Am J Med Sci. 2016;8(6):252-5.

47. Kumar, J. Morgagni hernia presenting as gastric outlet obstruction in an elderly male. Surg Case Rep. 20162016 Jul 18;2016(7).

48. Manipadam JM, Sebastian GM, Ambady V, Hariharan R. Perforated gastric gangrene without pneumothorax in an adult Bochdalek hernia due to volvulus. J Clin Diagn Res. 2016;10(4):D09-10.
49. Harada M, Tsujimoto H, Nagata K, Ito N, Yamazaki K, Kanematsu K, Horiguchi H, Kajiwara Y, Hiraki S, Aosasa S, Yamamoto J, Hase K. Successful laparoscopic repair of an incarcerated Bochdalek hernia associated with increased intra-abdominal pressure during use of blow gun: a case report. Int J Surg Case Rep. 2016;23:131-3.

50. Siow SL1,2, Wong CM3,4, Hardin M5, Sohail M6. Successful laparoscopic management of combined traumatic diaphragmatic rupture and abdomina wall hernia: a case report. J Med Case Rep. 2016 Jan 18;10:11. doi: 10.1186/ s13256-015-0780-8.

51. Andreev AL, Protsenko AV, Globin AV. Laparoscopic repair of a posttraumatic left-sided diaphragmatic hernia complicated by strangulation and colon obstruction. JSLS. 2010;14:410-3.

52. Bhatt NR, McMonagle M. Recurrence in a laparoscopically repaired traumatic diaphragmatic hernia: case report and literature review. Trauma Mon. 2016; 21:e20421.

53. Abdullah M1, Stonelake P2. Tension pneumothorax due to perforated colon. BMJ Case Rep. 2016 May 31;2016.

54. Razi K, Light D2, Horgan L2. Emergency repair of Morgagni hernia with partial gastric volvulus: our approach. Journal of Surgical Case Reports, 2016 J Surg Case Rep. 2016 Aug 31;2016(8).

55. Wigley J, Noble F, King A. Thoracoabdominal herniation-but not as you know it. Ann R Coll Surg Engl. 2014;96:e1-2

56. Atef M, Emna T. Bochdalek Hernia with gastric volvulus in an adult: common symptoms for an original diagnosis. Medicine (Baltimore). 2015;94:e2197.

57. Tokur M, Demiröz ŞM, Sayan M. Non-traumatic tension gastrothorax in a young lady. Ulus Travma Acil Cerrahi Derg. 2015;21(4):306-8.

58. Topuz M, Ozek MC. Right ventricle collapse secondary to hepatothorax caused by diaphragm rupture due to blunt trauma. Ulus Travma Acil Cerrahi Derg. 2014;20:463-5.

59. Haratake N, Yamazaki K, Shikada Y. Diaphragmatic hernia caused by heterotopic endometriosis in Chilaiditi syndrome: report of a case. Surg Today. 2015;45(9):1194-6.

60. Gali BM, Bakari AA, Wadinga DW, Nganjiwa US. Missed diagnosis of a delayed diaphragmatic hernia as intestinal obstruction: a case report. Niger J Med. 2014;23(1):83-5.

61. Newman MJ1. A mistaken case of tension pneumothorax. BMJ Case Rep. 2014 May 16;2014. pii: bcr2013203435.

62. Tyagi S, Steele J, Patton B, Fukuhara S, Cooperman A, Wayne M. Laparoscopic repair of an intrapericardial diaphragmatic hernia. Ann Thorac Surg. 2014;97(1):332-3.

63. Ota H, Kawai H, Matsuo T. Video-assisted minithoracotomy for blunt diaphragmatic rupture presenting as a delayed hemothorax. Ann Thorac Cardiovasc Surg. 2014;20(Suppl):911-4. doi:10.5761/atcs.cr.13-00201. Epub 2013 Nov 8.

64. Safdar G, Slater R, Garner JP. Laparoscopically assisted repair of an acute traumatic diaphragmatic hernia. BMJ Case Rep. 2013 Jun 24;2013.

65. Sonthalia N, Ray S, Khanra D, Saha A,Maitra S, Talukdar A; Gastric volvulus through morgagni hernia: an easily overlooked emergency. J Emerg Med. 2013

66. Nayak HK, Maurya G, Kapoor N, Kar P. Delayed presentation of congenital diaphragmatic hernia presenting with intrathoracic gastric volvulus: a case report and review. BMJ Case Rep. 2012;28:2012.

67. Vernadakis S, Paul A, Kykalos S, Fouzas I, Kaiser GM, Sotiropoulos GC. Incarcerated diaphragmatic hernia after right hepatectomy for living donor liver transplantation: case report of an extremely rare late donor complication. Transplant Proc. 2012:44(9):2770-2.

68. Ngai I, Sheen JJ, Govindappagari S, Garry DJ. Bochdalek hernia in pregnancy. BMJ Case Rep. 2012;11:2012.

69. Elangovan A, Chacko J, Gadiyaram S, Moorthy R. Ra traumatic tension gastrothorax and pneumothorax. J Emerg Med. 2013;44(2):e279-80.

70. Kuppusamy A, Ramanathan G, Gurusamy J, Ramamoorthy B, Parasakthi K. Delayed diagnosis of traumatic diaphragmatic rupture with herniation of the liver: a case report. Ulus Travma Acil Cerrahi Derg. 2012;18(2):175-7.

71. Okan I, Baş G, Ziyade S, Alimoğlu O, Eryılmaz R, Güzey D, Zilan A. Delayed presentation of posttraumatic diaphragmatic hernia. Ulus Travma Acil Cerrahi Derg. 2011;17(5):435-9.

72. Baloyiannis I, Kouritas VK, Karagiannis K, Spyridakis M, Efthimiou M. Isolated right diaphragmatic rupture following blunt trauma. Gen Thorac Cardiovasc Surg. 2011;59(11):760-2. doi:10.1007/s11748-010-0759-8. Epub 2011 Nov 15.

73. Vassileva CM, Shabosky J, Boley T, Hazelrigg S. Morgagni hernia presenting as a rigright middle lobe compression. Ann Thorac Cardiovasc Surg. 2012; 18(1):79-81. Epub 2011 Sep 29. 
74. Agrafiotis AC, Kotzampassakis N, Boudaka W. Complicated right-sided Bochdalek hernia in an adult. Acta Chir Belg. 2011;111(3):171-3.

75. Tan KK, Yan ZY, Vijayan A, Chiu MT. Management of diaphragmatic rupture from blunt trauma. Singap Med J. 2009;50(12):1150-3.

76. Akhtar K, Qurashi K, Rizvi A, Isla R. Emergency laparoscopic repair of an obstructed Bochdalek hernia in an adult. Br J Hosp Med (Lond). 2009;70(12):718-9.

77. Ozpolat B, Doğan OV, Yücel E. Delayed diaphragmatic hernia: an unusual complication of tube thoracostomy. Ulus Travma Acil Cerrahi Derg. 2009; 15(6):617-8.

78. Altinkaya N, Parlakgümüş A, Koc Z, Ulusan S. Morgagni hernia: diagnosis with multidetector computed tomography and treatment. Hernia. 2010;14(3):277-81.

79. Peer SM, Devaraddeppa PM, Buggi S. Traumatic diaphragmatic hernia-our experience. Int J Surg. 2009;7(6):547-9.

80. Sung HY, Cho SH, Sim SB, Kim Jl, Cheung DY, Park SH, Han JY, Lee SM, Noh $\mathrm{CH}$, Park YB, Jung SE, Lee SH, Choi KY. Congenital hemidiaphragmatic agenesis presenting as reversible mesenteroaxial gastric volvulus and diaphragmatic hernia: a case report. J Korean Med Sci. 2009;24(3):517-9.

81. Ouazzani A, Guerin E, Capelluto E, Landolfo G, Roman A, Bruyns J, Cadiere GB. A laparoscopic approach to left diaphragmatic rupture after blunt trauma. Acta Chir Belg. 2009;109(2):228-31.

82. Kavanagh DO, Ryan RS, Waldron R. Acta Chir Belg. Acute dyspnoea due to an incarcerated right-sided Bochdalek's hernia. 2008 Sep-Oct;108(5):604-6.

83. Hung YH, Chien YH, Yan SL, Chen MF. Adult Bochdalek hernia with bowel incarceration. J Chin Med Assoc. 2008;71(10):528-31.

84. Gourgiotis S, Rothkegel S, Germanos S. Combined diaphragmatic and urinary bladder rupture after minor motorcycle accident (report of a case and literature review). Ulus Travma Acil Cerrahi Derg. 2008;14(2):163-6.

85. Walchalk LR, Stanfield SC. Delayed presentation of traumatic diaphragmatic rupture. J Emerg Med. 2010;39(1):21-4.

86. Mohammadhosseini B, Shirani S. Incarcerated Bochdalek hernia in an adult. J Coll Physicians Surg Pak. 2008;18(4):239-41.

87. Boyce S, Burgul R, Pepin F, Shearer C. Late presentation of a diaphragmatic hernia following laparoscopic gastric banding. Obes Surg. 2008;18(11):1502-4.

88. Tsuboi K, Omura N, Kashiwagi H, Kawasaki N, Suzuki Y, Yanaga K. Delayed traumatic diaphragmatic hernia after open splenectomy: report of a case. Surg Today. 2008;38(4):352-4.

89. Vogelaar FJ, Adhin SK, Schuttevaer HM. Delayed intrathoracic gastric perforation after obesity surgery: a severe complication. Obes Surg. 2008;18(6):745-6.

90. Wu YS, Lin YY, Hsu CW, Chu SJ, Tsai SH. Massive ipsilateral pleural effusion caused by transdiaphragmatic intercostal hernia. Am J Emerg Med. 2008; 26(2):252. doi:10.1016/j.ajem.2007.04.018. e3-4.

91. Igai H, Yokomise H, Kumagai K, Yamashita S, Kawakita K, Kuroda Y. Delayed hepatothorax due to right-sided traumatic diaphragmatic rupture. Gen Thorac Cardiovasc Surg. 2007:55(10):434-6.

92. Rifki Jai S, Bensardi F, Hizaz A, Chehab F, Khaiz D, Bouzidi A. A late posttraumatic diaphragmatic hernia revealed during pregnancy by post-partum respiratory distress. Arch Gynecol Obstet. 2007;276(3):295-8. Epub 2007 Apr 4

93. Rout S, Foo FJ, Hayden JD, Guthrie A, Smith AM. Right-sided Bochdalek hernia obstructing in an adult: case report and review of the literature. Hernia. 2007;11(4):359-62. Epub 2007 Mar 7.

94. Campbell AS, O'Donnell ME, Lee J. Mediastinal shift secondary to a diaphragmatic hernia: a life-threatening combination. Hernia. 2007;11(4): 377-9. Epub 2007 Feb 13.

95. Luu TD, Reddy VS, Miller DL, Force SD. Gastric rupture associated with diaphragmatic hernia during pregnancy. Ann Thorac Surg. 2006;82(5):1908-10.

96. Iso Y, Sawada T, Rokkaku K, Furihata T, Shimoda M, Kita J, Kubota K. A case of symptomatic Morgagni's hernia and a review of Morgagni's hernia in Japan (263 reported cases). Hernia. 2006;10(6):521-4. Epub 2006 Aug 16.

97. Eglinton T, Coulter GN, Bagshaw P, Cross L. Diaphragmatic hernias complicating pregnancy. ANZ J Surg. 2006;76(7):553-7.

98. Barbetakis N, Efstathiou A, Vassiliadis M, Xenikakis T, Fessatidis. Bochdaleck's hernia complicating pregnancy: case report. World J Gastroenterol. 2006; 12(15):2469-71.

99. Barrett J, Satz W. Traumatic, pericardio-diaphragmatic rupture: an extremely rare cause of pericarditis. J Emerg Med. 2006;30(2):141-5.

100. Abboud B, Jaoude JB, Riachi M, Sleilaty G, Tabet G. Intrathoracic transverse colon and small bowel infarction in a patient with traumatic diaphragmatic hernia. Case report and review of the literature. J Med Liban. 2004;52(3): 168-70. Review.

101. Hsu YP, Chen RJ, Fang JF, Lin BC. Blunt diaphragmatic rupture in elderly patients. Hepatogastroenterology. 2005;52(66):1752-8.
102. Ransom P, Cornelius P. Stabbing chest pain: a case of intermittent diaphragmatic herniation. Emerg Med J. 2005;22(6):460-1.

103. Tiberio GA, Portolani N, Coniglio A, Baiocchi GL, Vettoretto N, Giulini SM. Traumatic lesions of the diaphragm. Our experience in 33 cases and review of the literature. Acta Chir Belg. 2005;105(1):82-8.

104. Gupta V, Singhal R, Ansari MZ. Spontaneous rupture of the diaphragm. Eur J Emerg Med. 2005;12(1):43-4.

105. Kara E, Kaya Y, Zeybek R, Coskun T, Yavuz C. A case of a diaphragmatic rupture complicated with lacerations of stomach and spleen caused by a violent cough presenting with mediastinal shift. Ann Acad Med Singapore. 2004;33(5):649-50.

106. Sirbu H, Busch T, Spillner J, Schachtrupp A, Autschbach R. Late bilateral diaphragmatic rupture: challenging diagnostic and surgical repair. Hernia. 2005;9(1):90-2. Epub 2004 Sep 3.

107. Dalton AM, Hodgson RS, Crossley C. Bochdalek hernia masquerading as a tension pneumothorax. Emerg Med J. 2004;21(3):393-4.

108. Niwa T, Nakamura A, Kato T, Kutsuna T, Tonegawa K, Kawai A, Itoh M. An adult case of Bochdalek hernia complicated with hemothorax. Respiration. 2003;70(6):644-6.

109. Genc MR, Clancy TE, Ferzoco SJ, Norwitz E. Maternal congenital diaphragmatic hernia complicating pregnancy. Obstet Gynecol. 2003;102(5 Pt 2):1194-6.

110. Sato $M$, Minimally invasive diagnosis and treatment of traumatic rupture of the right hemidiaphragm with liver herniation. Jpn J Thorac Cardiovasc Surg. 2002

111. Guven H, Malazgirt Z, Dervisoglu A, Danaci M, Ozkan K. Morgagni hernia: rare presentations in elderly patients. Acta Chir Belg. 2002;102(4):266-9.

112. Kanazawa A, Yoshioka Y, Inoi O, Murase J, Kinoshita H. Acute respiratory failure caused by an incarcerated right-sided adult bochdalek hernia: report of a case. Surg Today. 2002;32(9):812-5. Review.

113. Fisichella PM, Perretta S, Di Stefano A, Di Carlo I, La Greca G, Russello D, Latteri F. Chronic liver herniation through a right Bochdalek hernia with acute onset in adulthood. Ann Ital Chir. 2001;72(6):703-5.

114. Carreño G, Sánchez R, Alonso RA, Galarraga MA, Moriyón C, Magarzo A, Bouzón F, Makdissi Z, Obregón RA. Laparoscopic repair of Bochdalek's hernia with gastric volvulus. Surg Endosc. 2001;15(11):1359. Epub 2001 Aug 16.

115. Prieto Nieto I, Pérez Robledo JP, Rosales Trelles V, De Miguel IR, Fernández Prieto A, Calvo Celada A. Gastric incarceration and perforation following posttraumatic diaphragmatic hernia. Acta Chir Belg. 2001;101(2):81-3.

116. Nursal TZ, Ugurlu M, Kologlu M, Hamaloglu E. Traumatic diaphragmatic hernias: a report of 26 cases. Hernia. 2001;5(1):25-9.

117. Bujanda L, Larrucea I, Ramos F, Muñoz C, Sánchez A, Fernández I. Bochdalek's hernia in adults. J Clin Gastroenterol. 2001;32(2):155-7.

118. Pross M, Manger T, Mirow L, Wolff S, Lippert H. Laparoscopic management of a late-diagnosed major diaphragmatic rupture. J Laparoendosc Adv Surg Tech A. 2000;10(2):111-4.

119. Saito Y, Yamakawa Y, Niwa H, Kiriyama M, Fukai I, Kondo S, Fujii Y. Left diaphragmatic hernia complicated by perforation of an intrathoracic gastric ulcer into the aorta: report of a case. Surg Today. 2000;30(1):63-5.

120. De Waele JJ, Vermassen FE. Splenic herniation causing massive haemothorax after blunt trauma. J Accid Emerg Med. 1999;16(5):383-4.

121. Colliver C, Oller DW, Rose G, Brewer D, 1. Traumatic intrapericardial diaphragmatic hernia diagnosed by echocardiography. J Trauma. 1997;42(1):115-7.

122. Zantut LF, Machado MA, Volpe P, Poggetti RS, Birolini D. Bilateral diaphragmatic injury diagnosed by laparoscopy. Rev Paul Med. 1993;111(3):430-2.

123. Allen MS, Trastek VF, Deschamps C, Pairolero PC. Intrathoracic stomach. Presentation and results of operation. J Thorac Cardiovasc Surg. 1993;105(2): 253-8. discussion 258-9.

124. Girzadas Jr1 DV, Fligner DJ. Delayed traumatic intrapericardial diaphragmatic hernia associated with cardiac tamponade. Ann Emerg Med. 1991;20(11):1246-7.

125. Thomas S, Kapur B. Adult Bochdalek hernia_clinical features, management and results of treatment. Jpn J Surg. 1991;21(1):114-9.

126. Bush CA, Margulies R. Traumatic diaphragmatic hernia and intestinal obstruction due to penetrating trunk wounds. South Med J. 1990;83(11):1347-50. Review.

127. Feliciano DV, Cruse PA, Mattox KL, Bitondo CG, Burch JM, Noon GP, Beall Jr AC. Delayed diagnosis of injuries to the diaphragm after penetrating wounds. J Trauma. 1988;28(8):1135-44.

128. Chidamdaram M, Eyres KS, Szabolcs Z, Ionescu MI. Management problems of coincident traumatic diaphragmatic hernia and myocardial infarction. Thorac Cardiovasc Surg. 1988;36(3):167-9.

129. Symbas PN, Vlasis SE, Hatcher Jr C. Blunt and penetrating diaphragmatic injuries with or without herniation of organs into the chest. Ann Thorac Surg. 1986;42(2):158-62. 
130. Saber WL, Moore EE, Hopeman AR, Aragon WE. Delayed presentation of traumatic diaphragmatic hernia. J Emerg Med. 1986;4(1):1-7.

131. Gardezi SA, Chaudhry AM, Sial GA, Ahmad I, Rashid M, Yusuf A, Siddique S, Gardezi JR, Shafique T. Congenital diaphragmatic hernia in the adult. J Pak Med Assoc. 1986;36(1):16-20.

132. Brown GL, Richardson JD. Traumatic diaphragmatic hernia: a continuing challenge. Ann Thorac Surg. 1985;39(2):170-3.

133. Clark DE, Wiles 3rd CS, Lim MK, Dunham CM, Rodriguez A. Traumatic rupture of the pericardium. Surgery. 1983;93(2):495-503.

Submit your next manuscript to BioMed Central and we will help you at every step:

- We accept pre-submission inquiries

- Our selector tool helps you to find the most relevant journal

- We provide round the clock customer support

- Convenient online submission

- Thorough peer review

- Inclusion in PubMed and all major indexing services

- Maximum visibility for your research

Submit your manuscript at www.biomedcentral.com/submit
Biomed Central 